\title{
A New Stainless-Steel Tube-in-Tube Damper for Seismic Protection of Structures
}

\author{
Guillermo González-Sanz ${ }^{\mathbb{D}}$, David Escolano-Margarit ${ }^{\mathbb{D}}$ and Amadeo Benavent-Climent *(D) \\ Department of Mechanical Engineering, Universidad Politécnica de Madrid, 28006 Madrid, Spain; \\ guillermo.gonzalez.sanz@upm.es (G.G.-S.); d.escolano@upm.es (D.E.-M.) \\ * Correspondence: amadeo.benavent@upm.es; Tel.: +34-910-677-237
}

Received: 1 February 2020; Accepted: 17 February 2020; Published: 19 February 2020

Featured Application: The damper presented in this paper is applied for the protection of buildings subjected to strong earthquakes; in particular, for preventing or minimizing damage to the main structure and reducing its lateral displacements.

\begin{abstract}
This paper investigates a new stainless-steel tube-in-tube damper (SS-TTD) designed for the passive control of structures subjected to seismic loadings. It consists of two tubes assembled in a telescopic configuration. A series of slits are cut on the walls of the exterior tube in order to create a series of strips with a large height-to-width ratio. The exterior tube is connected to the interior tube so that when the brace-type damper is subjected to forced axial displacements, the strips dissipate energy in the form of flexural plastic deformations. The performance of the SS-TTD is assessed experimentally through quasi-static and dynamic shaking table tests. Its ultimate energy dissipation capacity is quantitatively evaluated, and a procedure is proposed to predict the failure. The cumulative ductility of the SS-TTD is about 4-fold larger than that reported for other dampers based on slit-type plates in previous studies. Its ultimate energy dissipation capacity is 3-and 16-fold higher than that of slit-type plates made of mild steel and high-strength steel, respectively. Finally, two hysteretic models are investigated and compared to characterise the hysteretic behaviour of the SS-TTD under arbitrarily applied cyclic loads.
\end{abstract}

Keywords: metallic damper; stainless steel; shaking table test; cyclic loading; energy dissipation

\section{Introduction}

For decades, seismic-resistant structures have been designed using the conventional approach of ensuring life safety against earthquakes, the main objective being to prevent buildings from collapsing. However, this approach comes at the cost of assuming important damage to the structure after the earthquake, requiring in most cases its demolition and rebuilding or a high cost of repair. Strong ground motions such as the Northridge (Northridge, 1994) or Hyogo-ken Nambu (Kobe, 1995) earthquakes have long since proven that this approach is no longer valid, as economic losses are also to be considered in seismic-resistant design. Controlling damage is a key aspect of the so-called Performance-Based Seismic Design: the new paradigm that has guided the development of codes, strategies and new technologies in the earthquake engineering field since the beginning of this century.

Substantial research efforts have been devoted to the development of innovative systems to control structures' vibration. These are categorized into four groups: passive systems, active systems, semi-active systems and hybrid systems [1-4]. Among them, passive control systems based on the use of displacement-dependent energy dissipation devices (EDDs) - also referred to herein as dampers-have been proven to be a cost-effective solution. When installed in the main structure, they can enhance the overall performance of the building, reducing the seismic response in terms of displacements and, 
more importantly, attracting most of the energy input by the earthquake. The damage concentrates in the EDDs, which are specifically engineered elements easy to inspect, repair and/or replace after an earthquake. This prevents damage to the main structure and minimizes disruption on the building use.

In displacement-dependent dampers, energy is dissipated through different mechanisms: metal yielding, metal phase transformation, friction, sliding, etc. Dampers based on metal yielding (metallic dampers) are made of materials with a large inherent plastic deformation capacity and shaped to avoid any source of stress concentration that could jeopardise the inherent high energy dissipation capacity of the material. Many metallic dampers have been developed in the last decades, and a state-of-the-art review of metallic dampers can be found in [5]. The original designs were based on simple torsion or bending of steel plates and uniaxial deformation of U-shape strips. Some widely used examples are: Buckling Restrained Braces, Added Damping and Stiffness, and its triangular version. Other energy dissipation devices that have drawn attention lately are the slit type (Figure 1a) and the honeycomb damper (Figure 1b). They are built from steel plates with openings of constant width referred to as slits (Figure 1a), or a variable honeycomb shape (Figure 1b), leaving between them steel strips of constant (Figure 1a) or variable (Figure 1b) width. These strips dissipate energy through plastic flexural/shear deformations.

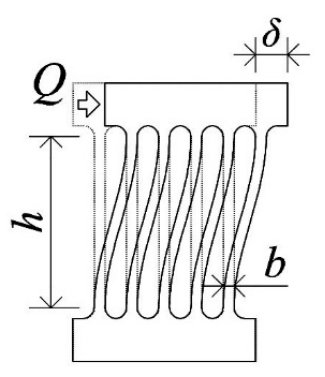

(a)

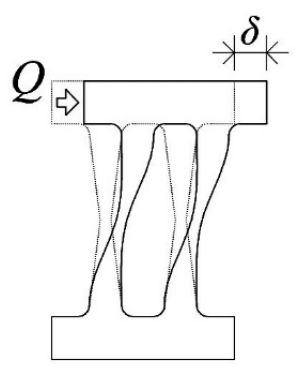

(b)

Figure 1. Metallic dampers: (a) slit damper; (b) honeycomb damper.

Several recent studies have investigated slit-type dampers made of mild steel. Chan [6] studied a slit damper fabricated from a standard structural wide-flange section with some slits cut in the web. Teruna [7] investigated several steel dampers with a honeycomb geometry with the aim of yielding all the length of the strip simultaneously. Lee [8] proposed several optimized nonuniform shapes for the openings of the damper and compared their overall performance through quasi-static cyclic tests. Lee [9] developed a series of hourglass-shaped strip dampers and tested them under quasi-static and dynamic monotonic and cyclic loading. Amiri [10] studied a symmetric slit damper cut from a steel plate having a low height-to-thickness ratio. The shape and dimensions of several specimens were optimized and tested experimentally under cyclic loading in quasi-static conditions. Extending the concept of the slit-type damper, Benavent [11] devised a tube-in-tube damper based on yielding the walls of hollow mild steel structural sections, which can be installed in a frame structure as a conventional diagonal brace. Past studies on slit-type dampers used steel plates made of mild steel, low-yield steel or even high-strength steel [12]. To the knowledge of the authors, slit-type dampers made of stainless steel have not been reported in the literature.

This study proposes a new Stainless-Steel Tube-in-Tube Damper (hereafter SS-TTD), whose source of energy dissipation is the plastic deformation of stainless-steel plates with slits. Besides the novelty of using stainless steel instead of mild or high-strength steel, SS-TTD uses strips with an $h / b$ aspect ratio (see Figure 1a) as large as possible within the dimensional constraints imposed for architectural reasons (i.e., in conventional buildings, the cross section of the tubes is limited so that the brace damper can be embedded in partitions or exterior walls). Stainless steel has an inherent energy dissipation capacity that is markedly larger than that of low-yield steel or mild steel. This is due to its higher ductility, that is, the amount of plastic deformation that the material can endure until failure [13]. Meanwhile, 
large $h / b$ ratios guarantee a flexural-type yielding mode of the steel strips and enhance the energy dissipation capacity of the damper. The performance of the SS-TTD in terms of hysteretic behaviour, ductility and ultimate energy dissipation capacity is investigated through dynamic shaking table tests and quasi-static cyclic tests. A comparison with other metallic dampers proposed in the literature is presented. Finally, two numerical models are proposed and compared, to predict the hysteretic behaviour and failure of the damper.

\section{Proposed Seismic Damper}

The proposed SS-TTD damper is constructed through the assemblage of two standardized stainless-steel tubes with a telescopic configuration (Figure 2a). All faces (i.e., the four walls) of the outer tube are regularly slit transversally to its longitudinal axis, forming strips. The strips are grooved so that one of its sides can be connected to a common plate, thus linking all in parallel. The common plate that gathers one end of each steel strip is fixed to the inner tube with plug welding at discrete points. The other end of each steel strip is connected to the corner of the outer tube. When the brace is subjected to axial forces, the relative displacements between the tubes impose a double curvature flexural deformation on the strips, which behave as a series of fixed-ended beams. These strips constitute the energy dissipating part of the SS-TTD. One end of each tube is connected to auxiliary brace members of the appropriate length that connect the SS-TTD damper to the two points of the building structure that are expected to undergo large relative horizontal displacements (Figure 2b). Typically, in frame structures, these points are two beam-column joints of consecutive spans and floor levels, as shown in Figure 2b.

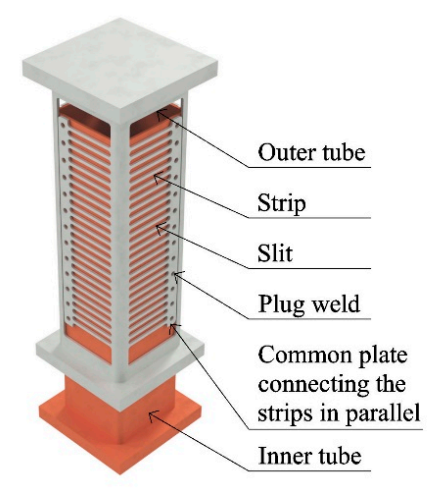

(a)

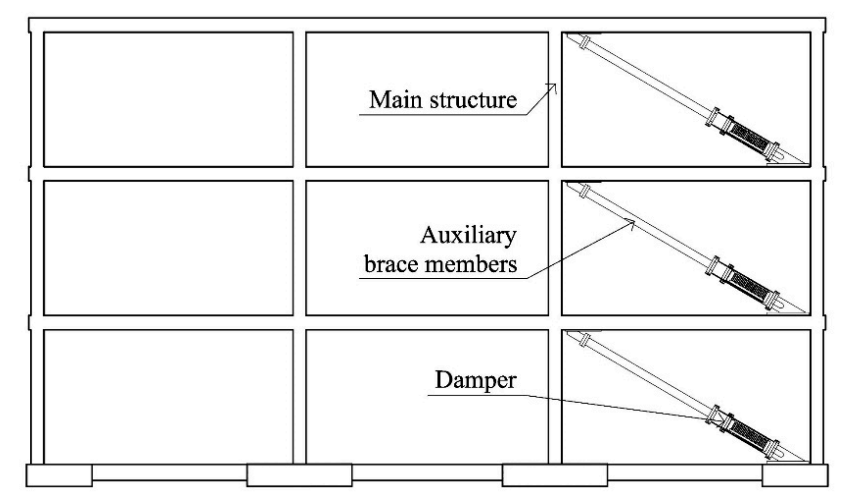

(b)

Figure 2. Proposed damper (a) and installation in a typical building frame (b).

Knowing the geometry and mechanical properties of the stainless steel that form the strips, the axial yielding force $Q_{y}$ and apparent maximum force $Q_{B}$ of the damper are readily obtained by applying fundamental engineering principles as follows:

$$
Q_{y}=n \frac{\sigma_{y} t b^{2}}{2 h^{\prime}} ; Q_{B}=n \frac{\sigma_{B} t b^{2}}{2 h^{\prime}}
$$

where $b$ and $t$ are the strip width and thickness, respectively, and $r$ is the radius at the extremes of the strips (see Figure 3a); $n$ is the total number of strips in the damper; $\sigma_{y}$ and $\sigma_{B}$ are the steel tensile stress at yielding and maximum states, and $h^{\prime}=h+\left[2 r^{2} /(h+2 r)\right]$ is the height of an equivalent strut where the actual round-shape ends are replaced by straight lines (see Figure $3 b$ ). The expression for $h^{\prime}$ was obtained by comparing the results of numerical analyses conducted with two different finite element models (Model 1 and Model 2) that represented one steel strip. In Model 1 the strip had rounded ends, as shown in Figure 3a. In Model 2 the actual rounded ends were replaced by straight lines defined, as shown in Figure 3b. A parametric study was conducted with different combinations of $r, h$ and 
$b$. For each combination, the value of the equivalent height $h^{\prime}$ that makes the strength and stiffness of the strip approximately equal (error less than 10\%) in Model 1 and in Model 2 was determined. The expression for $h^{\prime}$ was readily obtained by numerical regression of these results.

(a)

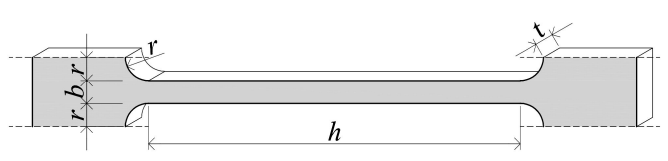

(b)

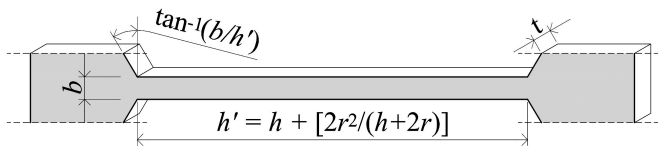

Figure 3. Geometry of the (a) actual and (b) equivalent strut.

The yielding displacement of the struts, $\delta_{y}$, can be estimated using the equivalent strip approximation of Figure $3 b$, by integration of the curvatures along the total height $h+2 r$ giving [11]:

$$
\delta_{y}=\frac{Q_{y} h^{\prime 3}}{n E t b^{3}}\left(1+3 \ln \frac{h+2 r}{h^{\prime}}\right) .
$$

Here $E$ is the Young's modulus of the material. The total axial displacement at yielding of the overall brace-type damper is readily obtained by adding to Equation (2) the elastic axial deformation of the inner and outer tubes, and the elastic deformation of the auxiliary brace members.

\section{Experimental Investigation}

The hysteretic behaviour and energy dissipation capacity of the SS-TTD were investigated experimentally. Two different types of test were conducted: (i) dynamic shaking table tests; and (ii) quasi-static cyclic tests. Three identical SS-TTDs, as shown in Figure 4, were built following the specifications described in Section 2. The outer and inner tubes were \#150.4 mm and \#140.4 mm (\#width.thickness) square hollow sections cut from a single segment. A total of 100 strips (25 per face) with dimensions of $b=5 \mathrm{~mm}, h=80 \mathrm{~mm}, t=4 \mathrm{~mm}$ and a radius of the ends of $r=5 \mathrm{~mm}$ were slit on the outer tube. Material tests were also conducted to determine the mechanical properties.
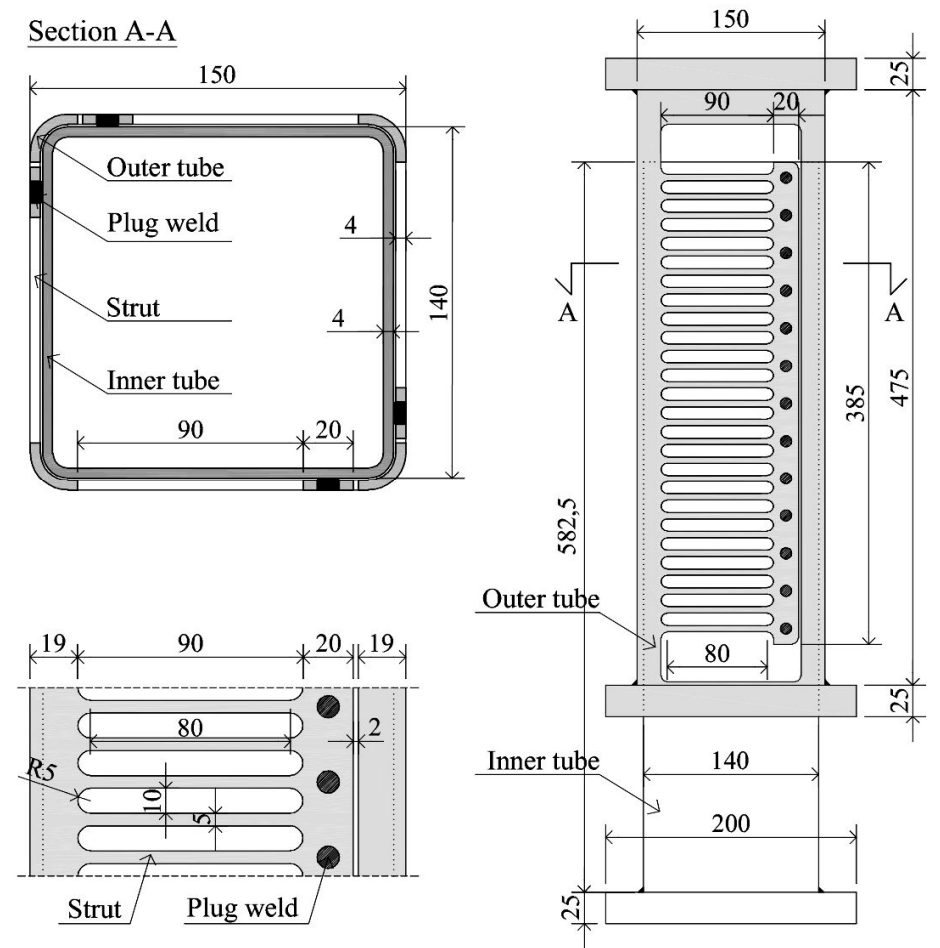

Figure 4. TTD damper specimen. 


\subsection{Material Testing}

All SS-TTD specimens were built with stainless steel, grade 1.4301 (304-L AISI). The material mechanical properties were obtained following the indications of ISO 6892-1:2016 [14] from standard coupon tension tests (Figure 5).

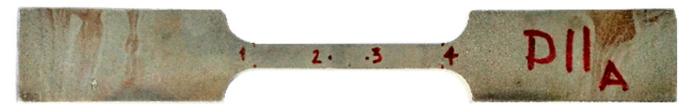

Figure 5. Coupon tension test specimen.

Since the dampers were studied under quasi-static and dynamic loads, the material was subjected to monotonic loading at two different strain rates of 0.003 and $0.115 \mathrm{~mm} / \mathrm{mm} / \mathrm{s}$, hereafter referred to as static and dynamic loadings, respectively. The strain rate is defined here as strain increments per second at the central section of the coupon tension test specimen (i.e., between points 2 and 3 in Figure 5), between zero strain and yield strain. Two specimens were tested at each strain rate.

Figure 6a shows the stress-strain curve obtained during the tests and a trilineal idealisation of the former. Table 1 summarizes the mean values and corresponding standard deviation of the main curve parameters obtained from direct tensile tests. In this table, $\sigma_{0.2 \%}$, is the $0.2 \%$ yielding stress (parameter commonly used to describe stainless steel), $\sigma_{u}$ is the ultimate stress, and $\varepsilon_{u}$ is the ultimate elongation. For convenience, the defining parameters of the trilinear approximation in Figure $6 \mathrm{~b}$ were included, namely: $\sigma_{y}, \varepsilon_{y}$ yielding stress and strain at the limit of proportionality; and $\sigma_{b}, \varepsilon_{b}$ stress and strain at the end of the smooth transition branch from elastic to inelastic range. The stress-strain curves were idealized as follows: (i) an initial linear-elastic branch following the modulus of elasticity $E$ until the limit of proportionality $\left(\sigma_{y}, \varepsilon_{y}\right)$; (ii) a second transition linear branch from $\left(\sigma_{y}, \varepsilon_{y}\right)$ to $\left(\sigma_{b}, \varepsilon_{b}\right)$ representing the transition curve; (iii) a final horizontal branch from $\left(\sigma_{b}, \varepsilon_{b}\right)$ to $\left(\sigma_{u}, \varepsilon_{u}\right)$ closely fitting the inelastic part. The values of $\sigma_{b}$ and $\varepsilon_{b}$ were determined so as the area under the real curve and the trilinear approximation was the same. As expected, the modulus of elasticity was the same in all tests, $E=2 \times 10^{5} \mathrm{MPa}$, irrespective of the strain rate applied. Table 1 also includes the theoretical values of $Q_{y}$ and $\delta_{y}$ obtained with Equations (1) and (2).

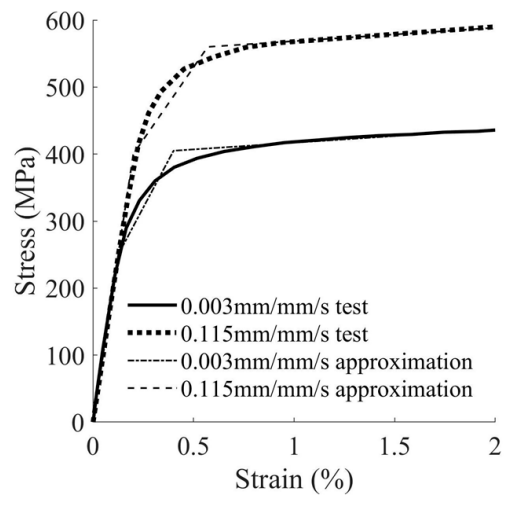

(a)

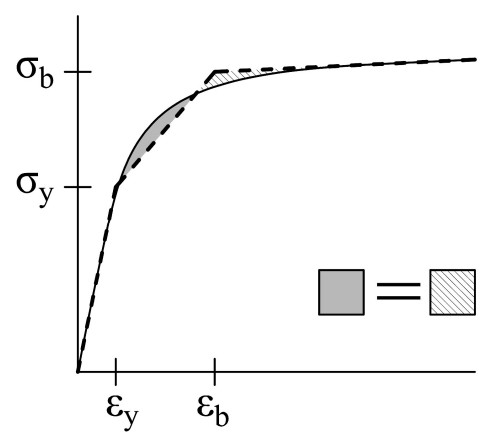

(b)

Figure 6. Stress-strain curves: (a) tension tests; (b) idealisation.

Table 1. Mechanical properties of the stainless steel at different strain rates.

\begin{tabular}{ccccccccccc}
\hline $\begin{array}{c}\text { Strain Rate } \\
\mathbf{m m} / \mathbf{m m} / \mathbf{s}\end{array}$ & $\begin{array}{c}\sigma_{\mathbf{0 . 2} \%} \\
\mathbf{M P a}\end{array}$ & $\begin{array}{c}\sigma_{\boldsymbol{u}} \\
\mathbf{M P a}\end{array}$ & $\begin{array}{c}\sigma_{\boldsymbol{y}} \\
\mathbf{M P a}\end{array}$ & $\boldsymbol{Q}_{\boldsymbol{y}} \mathbf{k N}$ & $\begin{array}{c}\sigma_{\boldsymbol{b}} \\
\mathbf{M P a}\end{array}$ & $\mathbf{Q}_{\boldsymbol{b}} \mathbf{k N}$ & $\boldsymbol{\varepsilon}_{\boldsymbol{y}} \%$ & $\delta_{\boldsymbol{y}} \boldsymbol{m} \boldsymbol{m}$ & $\varepsilon_{\boldsymbol{b}} \%$ & $\boldsymbol{\varepsilon}_{\boldsymbol{u}} \%$ \\
\hline 0.003 & $377 \pm 15$ & $604 \pm 30$ & $250 \pm 5$ & 15.50 & $405 \pm 15$ & 25.14 & $0.12 \pm 0.05$ & 1.08 & $0.40 \pm 0.01$ & $46 \pm 1$ \\
0.115 & $529 \pm 6$ & $709 \pm 16$ & $400 \pm 10$ & 24.83 & $560 \pm 15$ & 34.76 & $0.20 \pm 0.01$ & 1.73 & $0.57 \pm 0.02$ & $44 \pm 2$ \\
\hline
\end{tabular}




\subsection{Shaking Table Dynamic Tests}

In order to assess the performance of the damper against realistic earthquake-type dynamic loading, six SS-TTDs were installed in a reinforced concrete (RC) structure and tested with the shaking table of the Laboratory of Structural Dynamics of the University of Granada, Spain. The RC structure represents, at 2/5 scale, a portion of a prototype building structure consisting of RC waffle-flat plates supported on isolated RC columns. The prototype structure is shown in Figure 7. The portion of the structure that was selected and built in the laboratory is enclosed with dashed lines. The circles in Figure 7 indicate the sections (located at mid span of the plate and at mid height of the columns) where the bending moment is assumed to be zero under horizontal loads. The prototype structure was designed to sustain gravity loads only, according to the Spanish construction codes $[15,16]$. Figure 8 shows the portion of the prototype RC structure with the SS-TTDs mounted on the shaking table. As seen in Figure 8, three SS-TTDs were installed in each storey as diagonal bars. The three identical SS-TTDs shown in Figure 4 were installed in the upper storey, and will be referred to as SS-TTD4, SS-TTD5 and SS-TTD6. Reactive steel blocks were located at the top columns and on the waffle-flat plate to reproduce the mass of the upper part of the structure and to satisfy similitude laws. Figure 9 shows the overall experimental set-up. A detailed description of a similar reinforced structure tested by the authors in previous studies and with a different type of damper can be found in [17].

The seismic tests were performed with a bidirectional MTS $3 \times 3 \mathrm{~m}^{2}$ shaking table. The setup of instrumentation included uniaxial accelerometers, displacement transducers (LVDTs) and more than 400 strain gauges set in the whole structure. On the SS-TTDs, a pair of LVDTs for each damper measured the mean values of the relative axial displacements between the tubes. Axial forces were obtained as the average value from six strain gauges fixed to the auxiliary square hollow sections (\#80.4 mm) connecting the SS-TTD to the main structure. Figure 8 shows the test specimen equipped with the SS-TTDs and the setup and instrumentation utilized.

The RC structure with the SS-TTDs was subjected to eight seismic simulations. In all simulations the two horizontal components, north-south (NS) and east-west (EW), of ground motion acceleration recorded at Bar-Skupstina Opstine during the Montenegro earthquake (1979) were simultaneously applied, scaled in amplitude by a factor that was successively increased from $15 \%$ of the original record to $190 \%$. The NS component was applied in the direction of the axis of symmetry of the test specimen (referred to as direction $X$ ), and the EW component in the orthogonal direction (referred to as direction $Y$ ). Figure 10 shows the histories of acceleration applied to the shaking table in the $X$ and $Y$ horizontal directions. Figure 11 shows the movements of the reactive steel blocks located at the top of the columns of the upper storey; more precisely, the relative displacements in the $\mathrm{X}$ and $\mathrm{Y}$ horizontal directions with respect to the RC waffle-flat plate, and the rotations about the vertical axis passing through the centre of mass. It can be seen that the relative displacements in the $Y$ direction (Figure 11b) are about two times larger than in the $X$ direction (Figure 11a). The corresponding maximum inter storey drifts (i.e., the relative displacement divided by the height of the columns) were about $1 \%$ in the $\mathrm{X}$ direction and $2 \%$ in the $\mathrm{Y}$ direction. These values are below the limit of $2.5 \%$ associated with the performance level of life safety, and far below the $4 \%$ associated with collapse in previous studies on RC waffle-flat plate systems [17]. This means that the SS-TTDs protected the structure against collapse and kept it within reasonable levels of safety when subjected to ground motions with peak ground accelerations as large as $1 g$ (here $g$ is the acceleration of gravity), as shown in Figure 10. 


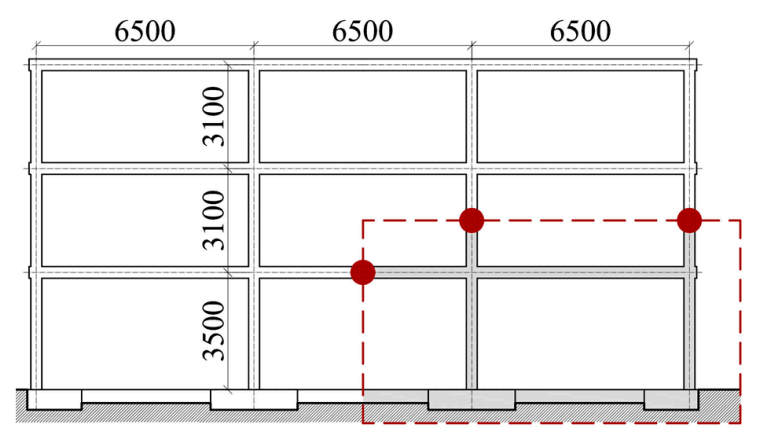

Figure 7. Sketch of the whole structure.

(a)

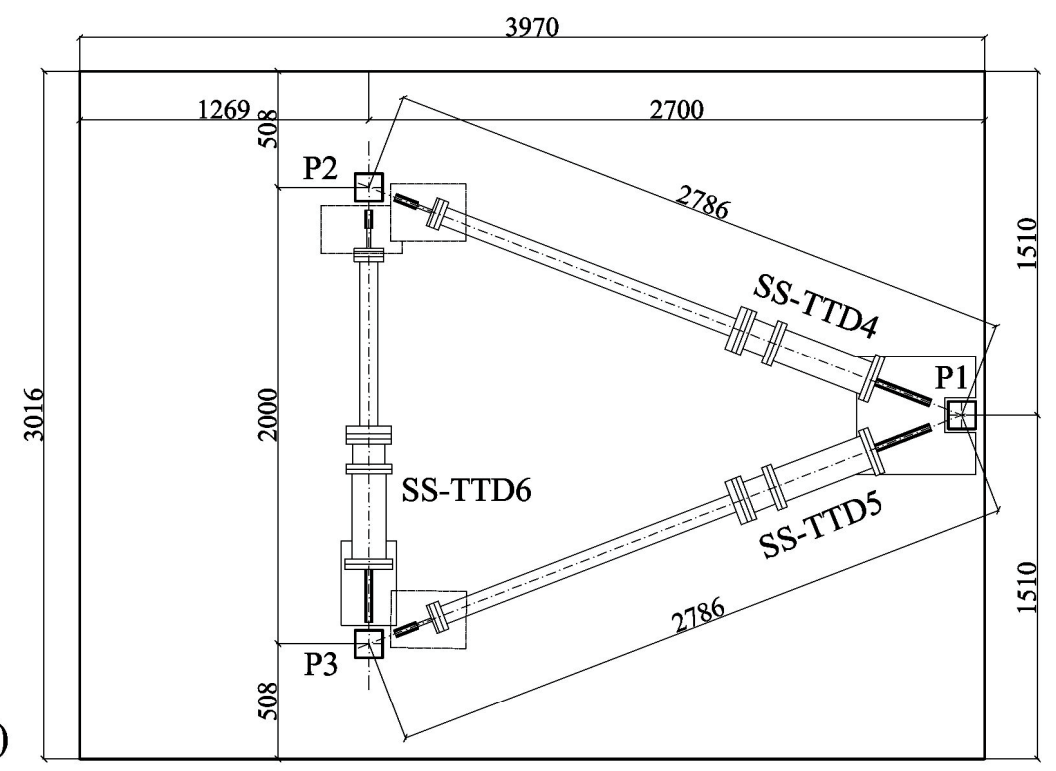

(b)

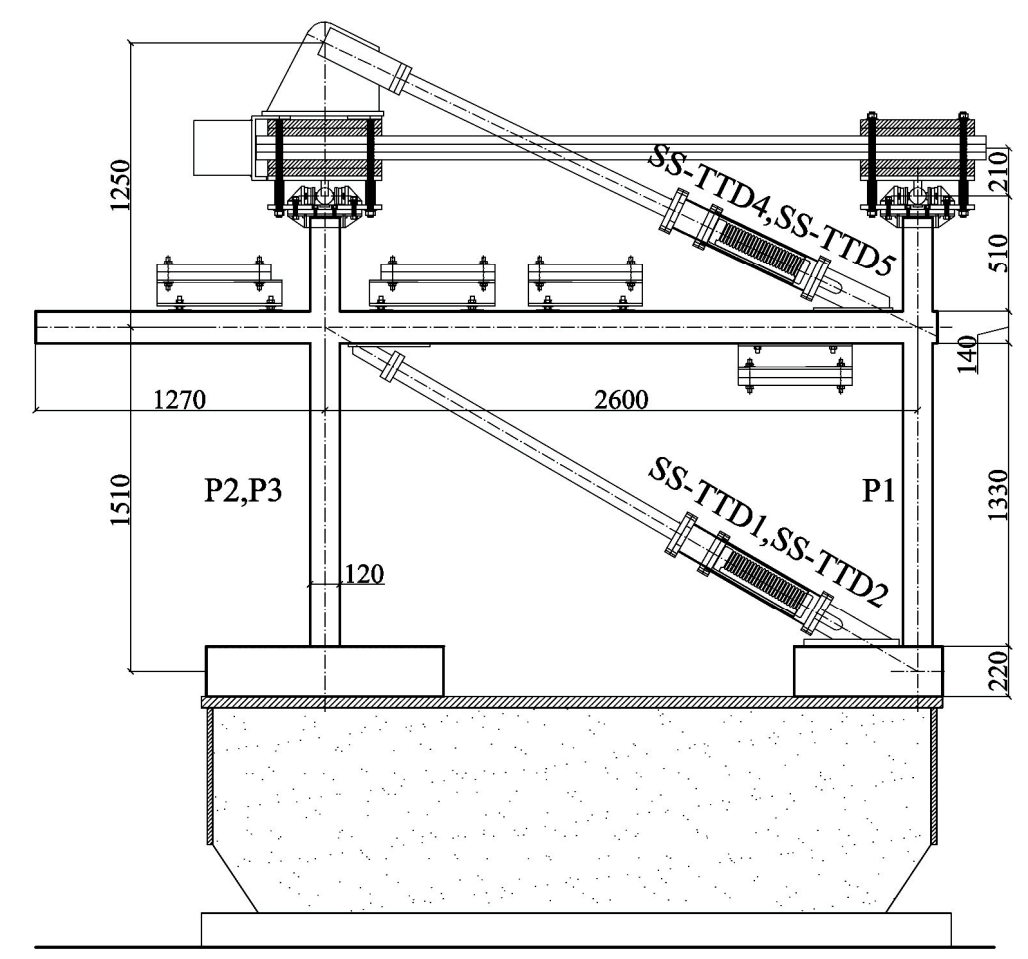

Figure 8. RC structure with SS-TTDs. (a) View in plan and (b) in elevation. 


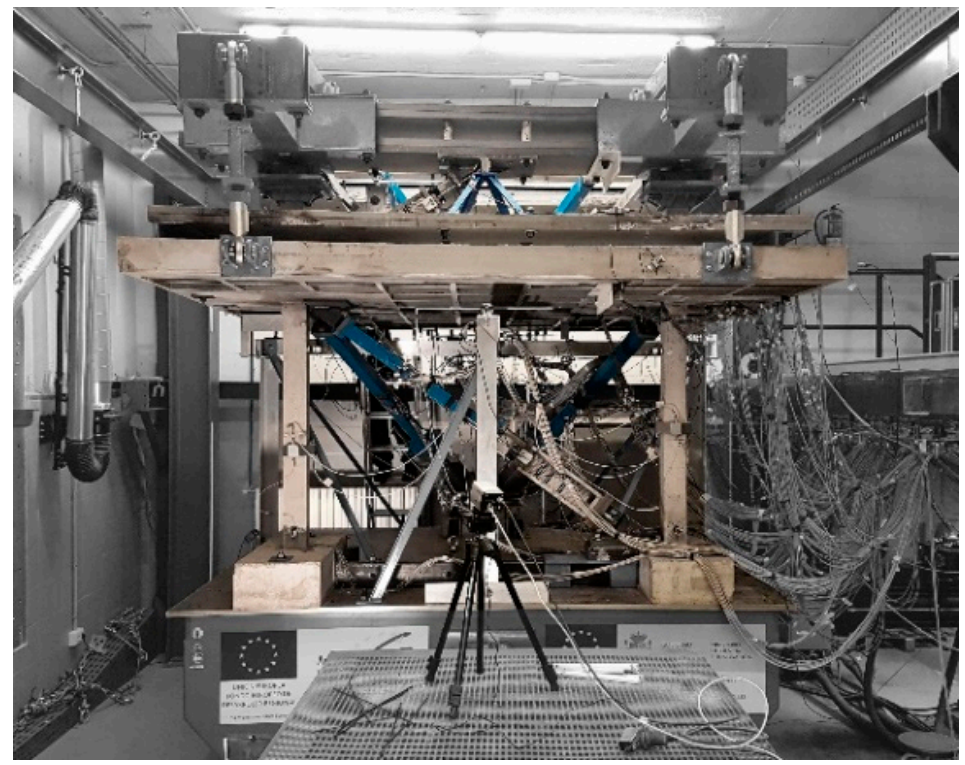

Figure 9. General overview of the experimental setup used for the shaking table tests.

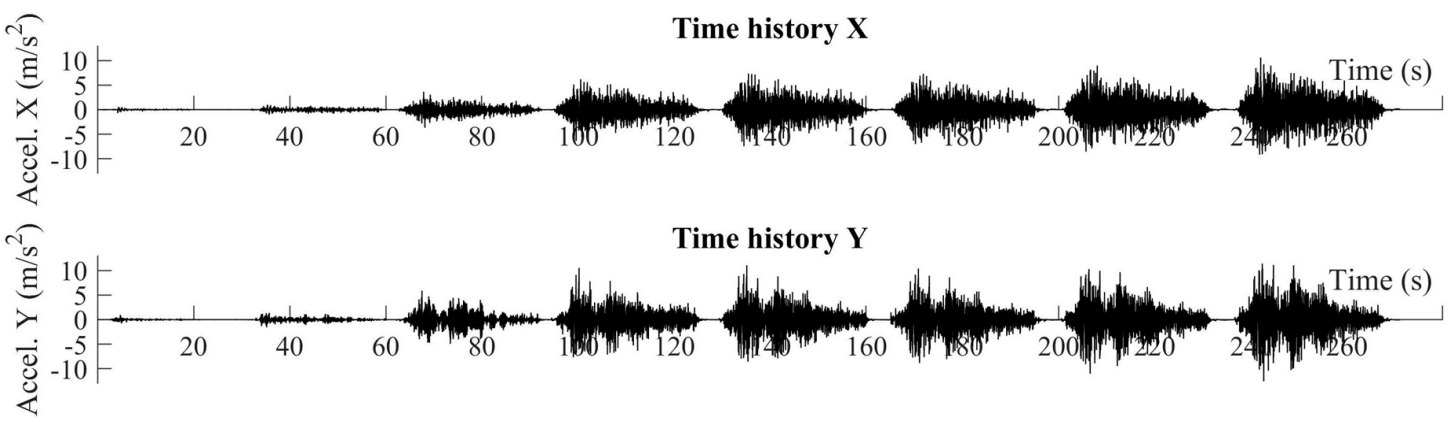

Figure 10. History of accelerations applied to the shaking table.

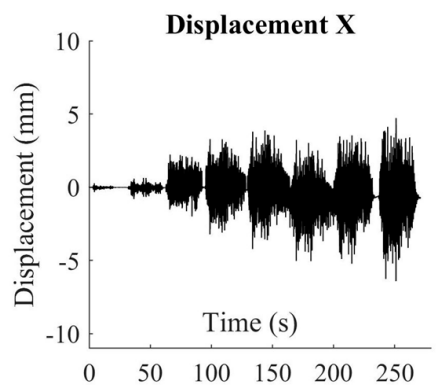

(a)

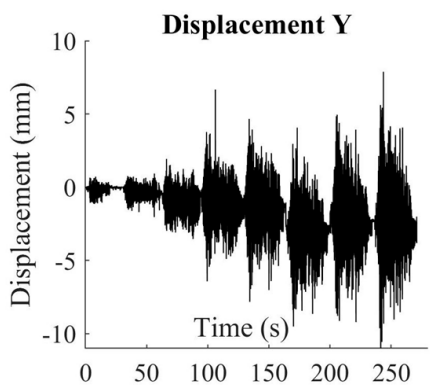

(b)

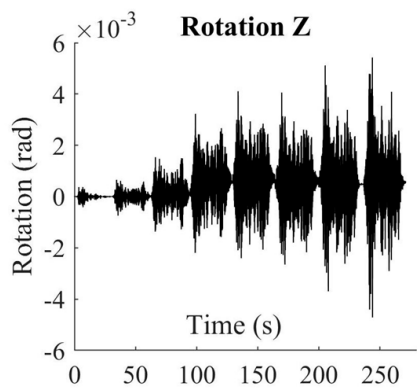

(c)

Figure 11. History of displacements and rotations of the reactive steel blocks located at the top of the columns of the upper storey during the shaking table tests: relative displacement in the $\mathrm{X}(\mathbf{a})$ and $\mathrm{Y}(\mathbf{b})$ horizontal directions, and rotation (c) about the axis passing through its centre of mass.

In the 1st, 2nd and 3rd seismic simulations the SS-TTDs remained elastic with maximum axial displacements of $0.2 \delta_{y D Y N}, 0.5 \delta_{y D Y N}$ and $0.9 \delta_{y D Y N}$. During the following seismic simulations, the SS-TTDs underwent plastic deformations and reached maximum axial displacements of up to $5.2 \delta_{y D Y N}$. This study focuses on the results obtained from the SS-TTDs located on the upper floor, namely SS-TTD4, SS-TTD5, and SS-TTD6. The overall response in terms of axial force vs. axial displacement of these SS-TTDs can be seen in Figure 12. At the end of the seismic simulations, the main 
RC structure (columns and waffle-flat slab) remained basically elastic (i.e., with no damage); the steel reinforcement did not experience any plastic deformation and only minor cracking was observed in the concrete. In contrast, the SS-TTD endured large plastic deformations but without failure, i.e., the SS-TTDs did not reach their ultimate energy dissipation capacity.

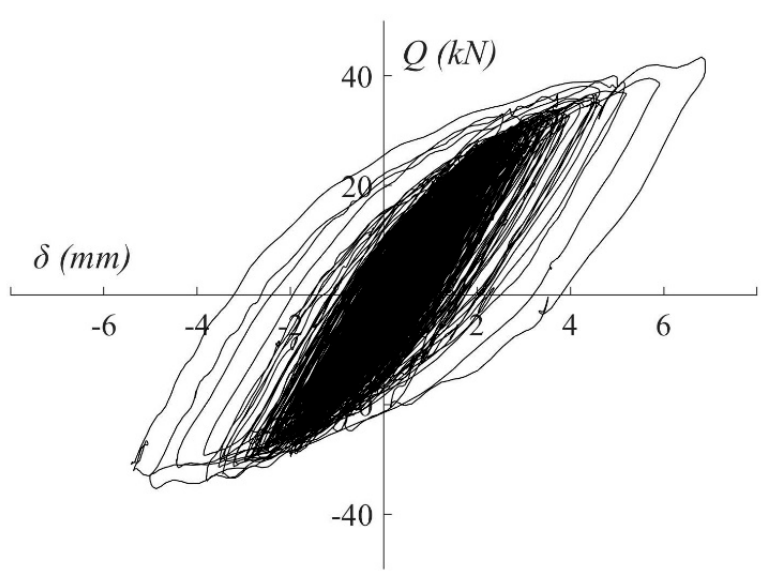

(a)

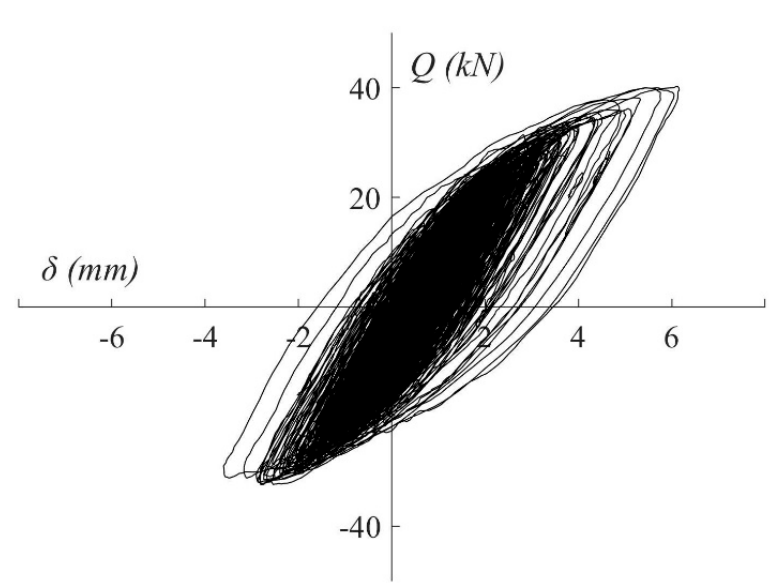

(b)

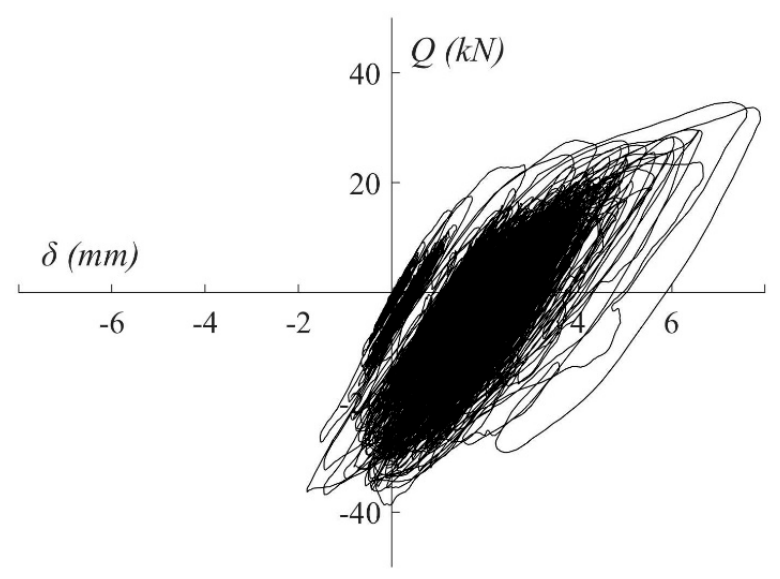

(c)

Figure 12. $Q-\delta$ curves obtained from the shaking table tests: (a) SS-TTD4, (b) SS-TTD5, (c) SS-TTD6. 


\subsection{Quasi-Static Cyclic Tests}

After performing the shaking table dynamic tests, the SS-TTDs installed in the upper storey were subjected to cyclic quasi-static loading until failure in order to quantify their ultimate energy dissipation capacity. The specimens were disassembled from the RC structure and tested on a SAXEWAY T1000 universal testing machine with a maximum load capacity of $1000 \mathrm{kN}$, as shown in Figure 13. Both the inner and outer tube were welded to a $25-\mathrm{mm}$ base plate that was rigidly bolted to the base of the testing machine and to the actuator, respectively. All the tests were carried out under displacement control with the same cyclic rate of $0.02 \mathrm{~Hz}$. Two displacement transducers (LVDTs), connecting the inner and outer tubes in the direction of the applied load, controlled and measured relative displacements between the tubes. Three different loading histories consisting of cyclic forced displacements were applied to the SS-TTDs. Specimen SS-TTD4 was subjected to an initial displacement of $10 \mathrm{~mm}$ in the positive direction followed by cycles of constant amplitude equal to 5 times the yield displacement $\delta_{y S T}$. Specimens SS-TTD5 and SS-TTD6 were subjected to sequential sets of cycles with incremental amplitude, following the protocol proposed by ATC [18]. In both cases the increment of displacement amplitude from one set of cycles to the next, $\Delta \delta$, was $\Delta \delta / \delta_{Y_{s t}}=1$; the difference was the number of cycles $n_{c}$ applied within each set. For specimen SS-TTD5 $n_{c}=10$, while for specimen SS-TTD6 $n_{c}=4$. The SS-TTD damper was assumed to fail when the force under increasing displacements dropped below $20 \%$ of the maximum force attained in previous cycles of deformation.

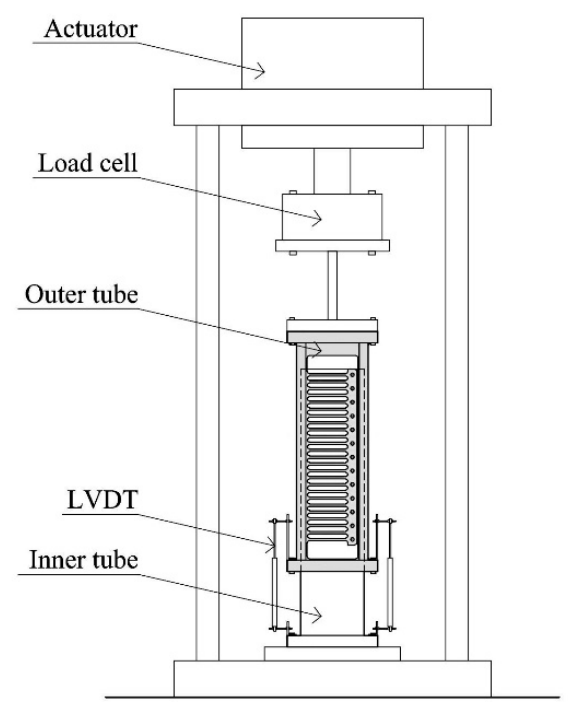

(a)

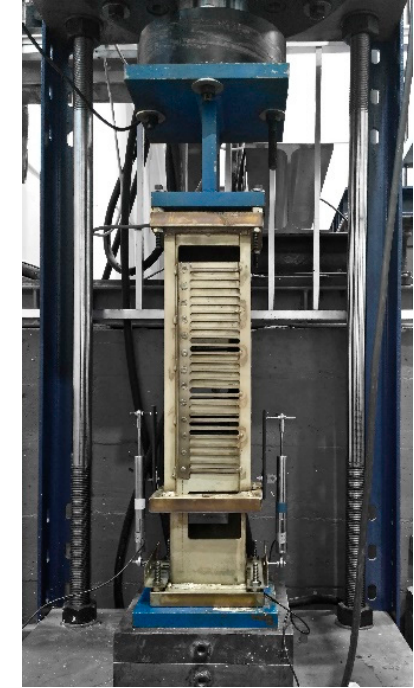

(b)

Figure 13. Experimental setup for static cyclic tests: (a) identification of components, (b) photograph.

The entire axial force-displacement, $Q-\delta$, hysteretic curves obtained from the quasi-static cyclic tests are plotted in dotted lines in Figure 14. The solid line represents the hysteretic behaviour before failure, with the dotted lines showing the $Q-\delta$ curves after failure. 


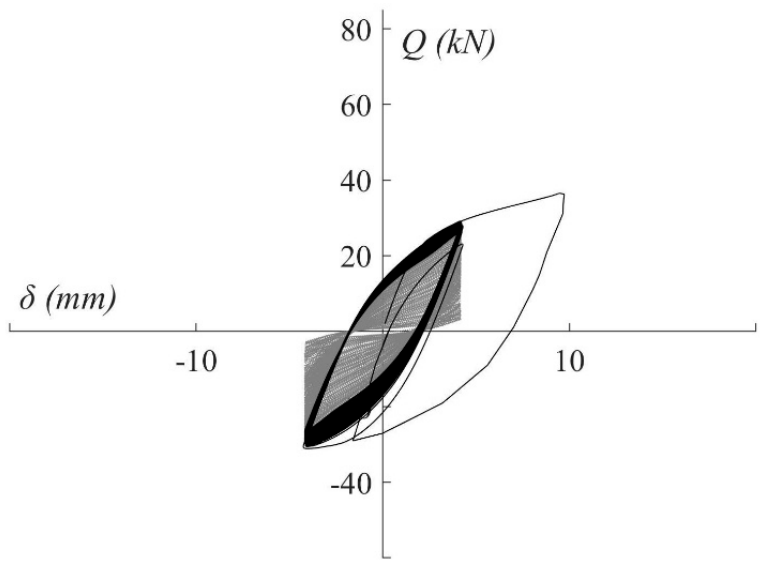

(a)

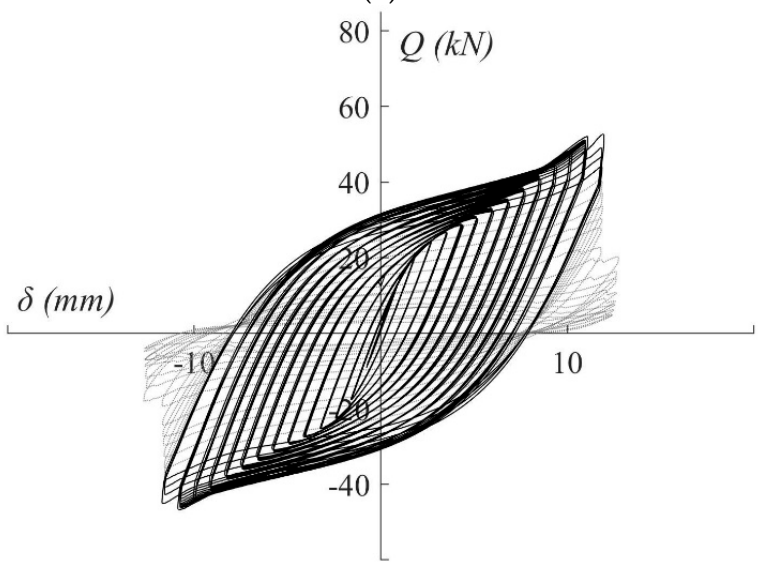

(b)

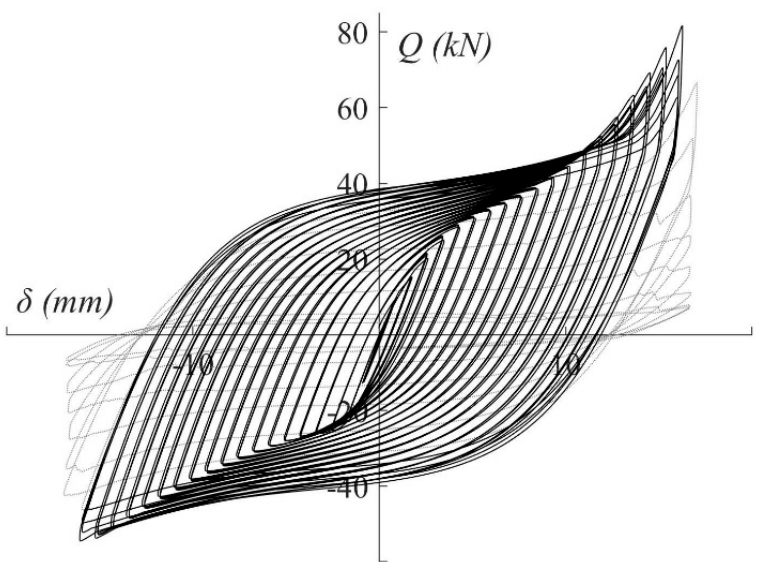

(c)

Figure 14. $Q-\delta$ curves obtained from the quasi-static cyclic tests: (a) SS-TTD4, (b) SS-TTD5, (c) SS-TTD6.

\section{Results and Discussion}

\subsection{Hysteretic Behaviour}

The seismic performance of the SS-TTDs is readily characterised in the complete load-displacement $Q-\delta$ hysteretic curves of Figure 15; it combines the curves obtained from the shaking table tests and from the quasi-static tests. Since the yield force and yield displacement are different under quasi-static (i.e., $Q_{y S T}=15.5 \mathrm{kN}, \delta_{y S T}=1.08 \mathrm{~mm}$ ), and under dynamic loads (i.e., $Q_{y D Y N}=24.83 \mathrm{kN}$, $\delta_{y D Y N}=1.73 \mathrm{~mm}$ ) due to strain rate effects [19-21], prior to combining the $Q-\delta$ curves they were 
normalized by the corresponding yielding force and yielding displacement. From the $Q-\delta$ curves shown in Figure 15 the following observations can be made. First, the SS-TTD exhibits a stable hysteretic behaviour. Second, the $Q-\delta$ curves under repeated cycles of the same amplitude are almost coincident, that is, the reduction of the peak strength under repeated cycles of constant amplitude is small. Third, second order effects due to strip geometric nonlinearity appear when the imposed displacements are very large, more precisely at displacement ductility $\mu=\delta_{\max } / \delta_{y S T}$ above 12 . This geometric nonlinearity results in a spurious increase of the restoring force. It must be noted, however, that the value of the ductility $\mu$ (i.e., about 12) beyond which the geometric nonlinearity effects become significant is far beyond the realistic range of lateral displacements that could be allowed in actual structures equipped with dampers. More precisely, in flexible RC frames or RC waffle-flat plate systems, damage starts for interstorey drifts, $I D$, between 0.005 and 0.01 times the storey height $H[17,22]$. Even if some (moderate) damage is allowed in the RC structure to reduce the cost of the dampers, the ID should not exceed about $0.015 \mathrm{H}$, because otherwise installing the dampers would be meaningless. Assuming a realistic storey height (after scaling by the scaling factor of the test specimen 2/5) of $H=3000 \times 2 / 5=1200 \mathrm{~mm}$, and an angle of the SS-TTD axis with the horizontal $\alpha=0.46 \mathrm{rad}$, the maximum axial displacement $\delta_{\max }(=H \times I D \times \cos \alpha)$ normalized by the yield displacement $\delta_{y D Y N}(=1.73 \mathrm{~mm})$, i.e., $\delta_{\max } / \delta_{y D Y N}$, to be allowed in the SS-TTD to prevent damage in the main RC structure would range between 3.1 and 6.2, and should be smaller than 9.3 in any case. These values are below the axial displacement ductility $\mu$ $(=12)$ corresponding to the onset of the second order effects.

The shape of the hysteretic loop $Q-\delta$ obtained in one cycle of imposed deformation at maximum amplitude $\delta_{\max }$ is typically characterised by the equivalent viscous ratio $\xi$, defined as follows:

$$
\xi=\frac{1}{2 \pi} \frac{W_{c}}{Q_{\max } \delta_{\max }},
$$

where $W_{c}$ is the energy dissipated in one cycle and $Q_{\max }$ the force attained at $\delta_{\max }$. This formula is obtained by equating the hysteretic energy dissipated in one cycle and the energy dissipated through viscous damping by means of an equivalent viscous damper in one cycle of harmonic vibration [23]. The larger $\xi$ is, the closer the shape of the hysteretic loop to an ideal parallelogram. $\xi$ was calculated for the hysteretic loops obtained from the SS-TTDs subjected to cycles of incremental amplitude; the results are displayed in Figure 16 against the amplitude of the cycle $\delta_{\max }$ normalized by $\delta_{y}$. It can be seen that for practical values of $\delta_{\max } / \delta_{y}$ (between approximately 6.2 and 9.3), the equivalent viscous damping $\xi$ remains approximately constant at $30 \%$. This value is compared in the last column of Table 2 with the $\xi$ 's obtained in previous studies $[6-8,10]$ for slit-type plates with different geometries $(h, b, t$ shown in Figure 3$)$ and material properties of the steel $\left(\sigma_{Y}\right)$. It can be seen that the value of $\xi$ for the damper proposed in this study is within the range (30\%-51\%) found for other types of dampers in previous studies, although in the lower bound. This means that the proposed damper does not present advantages in comparison to other dampers from the point of view of the amount of energy that can be dissipated per cycle for fixed values of $Q_{\max }$ and $\delta_{\max }$. Table 2 also shows the accumulated inelastic deformation ratio, $\eta$, and the cumulative ductility factor [6-11], $\mu_{C U M}$, that are typical parameters used to characterise the performance of dampers. These parameters are defined later in Equations (5) and (7), respectively. 


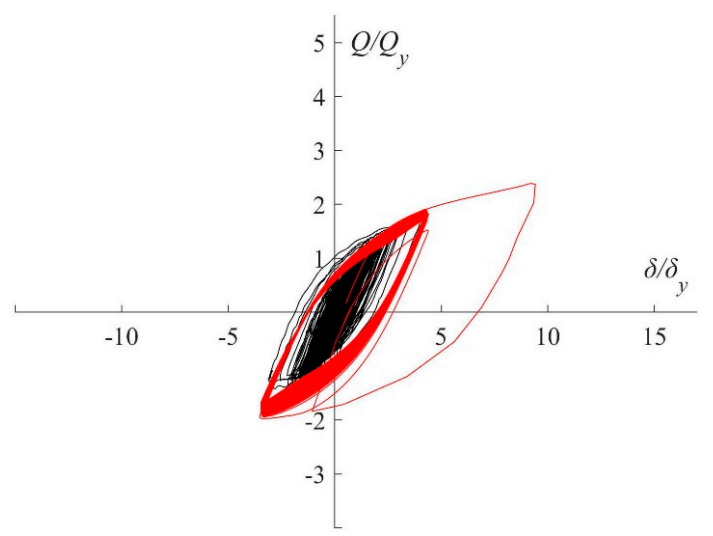

(a)

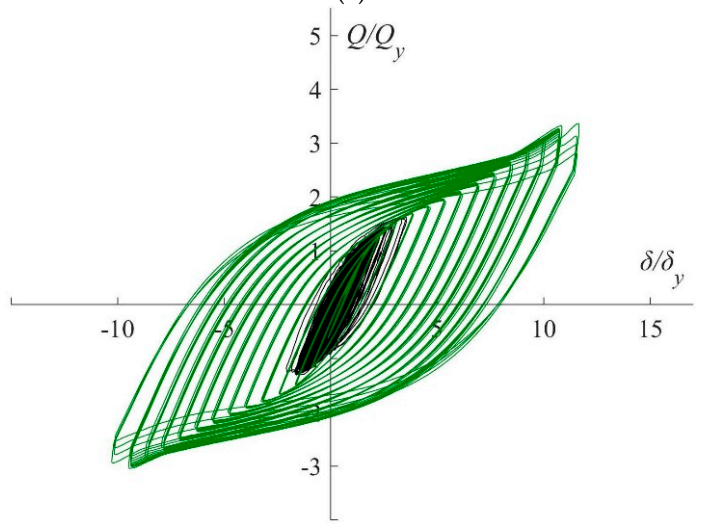

(b)

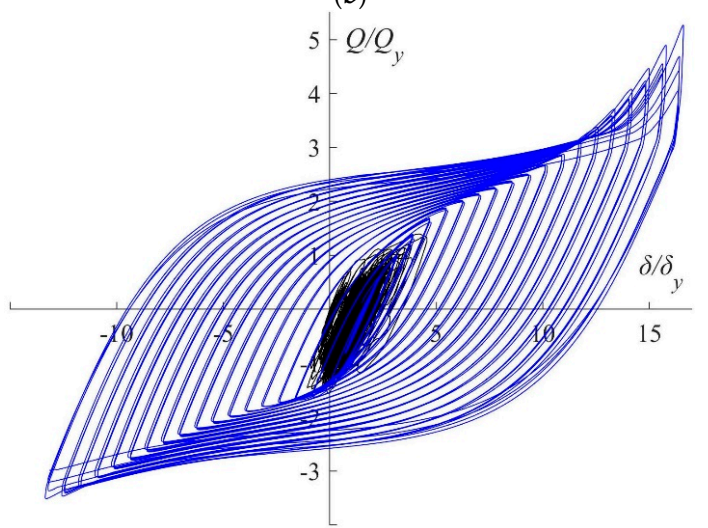

(c)

Figure 15. Total normalized $Q-\delta$ curves of the tested specimens: (a) SS-TTD4, (b) SS-TTD5, (c) SS-TTD6.

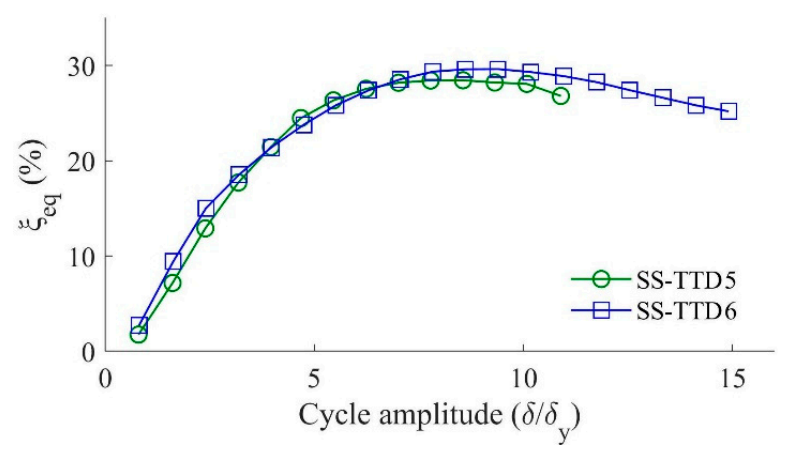

Figure 16. Equivalent viscous damping $\xi$ versus the normalized cycle amplitude. 
Table 2. Comparison with other slit-type steel plate dampers.

\begin{tabular}{ccccccccccc}
\hline & $\mathbf{h}$ & $\mathbf{b}$ & $\mathbf{t}$ & $\boldsymbol{\sigma}_{\mathbf{y}}$ & $\boldsymbol{\delta}_{\mathbf{y}}$ & $\mathbf{Q}_{\mathbf{y}}$ & $\boldsymbol{\mu}$ & $\boldsymbol{\mu}_{\mathbf{C U M}}$ & $\eta$ & $\xi$ \\
\hline Reference & $\mathbf{( m m )}$ & $\mathbf{( m m )}$ & $\mathbf{( m m )}$ & $\mathbf{( M P a )}$ & $\mathbf{( m m )}$ & $\mathbf{( k N )}$ & & & & $\mathbf{( \% )}$ \\
\hline Chan [6] & $77-99$ & $15-17$ & 8 & 316 & $1.2-1.7$ & $11.5-17.5$ & $8-11$ & $380-490$ & $370-460$ & $30-50$ \\
Teruna [7] & 240 & $70-90^{*}$ & 20 & 292 & $2.5-3.4$ & $114-176$ & $10-20$ & $80-125$ & $325-700$ & $40-50$ \\
Lee [8] & 180 & $30-36^{*}$ & 10 & 300 & $0.8-1.2$ & $73-83$ & $30-38$ & $380-660$ & $1200-2200$ & $44-51$ \\
Lee [9] & 180 & $36^{*}$ & 10 & 308 & $1.0-1.5$ & $78-89$ & $20-35$ & $370-480$ & $1000-1400$ & - \\
Amiri [10] & 80 & $14-28^{*}$ & 20 & 241 & $1.1-1.5$ & $30-71$ & $20-28$ & $390-480$ & $558-642$ & $36-43$ \\
Benavent [11] & $20-80$ & $15-20$ & $8-12$ & 449 & $0.2-0.5$ & $51-332$ & $30-60$ & $480-720$ & $407-774$ & - \\
This study & 80 & 5 & 4 & $250-400$ & $1.1-1.7$ & $15.5-24.8$ & $12-17$ & $1728-2707$ & $3332-3766$ & 30 \\
\hline
\end{tabular}

* Nonuniform shape (dimensions at the ends of the strip).

\subsection{Ultimate Energy Dissipation Capacity and Prediction of Failure}

Previous studies [24-26] have pointed out the dependence of the ultimate energy dissipation capacity of structural members subjected to low-cycle fatigue on the pattern of loading applied. An appropriate way $[24,25]$ to take into account this dependency consists of splitting the total energy dissipated by the damper into two parts: the energy dissipated on the so-called skeleton part and the energy dissipated on the Bauschinger part, as shown in Figure 17. The typical Q- $\delta$ curve obtained by testing a steel component under arbitrarily applied cyclic loads until failure (Figure 17a) can be decomposed into the skeleton part (Figure 17b) and Bauschinger part (Figure 17c) as follows. The skeleton part is formed, in each domain of loading, by connecting sequentially the segments of the $Q-\delta$ curve whose force $Q$ exceeds the maximum force attained in previous cycles in the same domain of loading. The skeleton curves obtained in this way coincide with the $Q-\delta$ obtained by subjecting the steel component to monotonic loadings [25]. The skeleton curves are idealized by the trilinear curve in Figure $17 \mathrm{~b}$ (dashed and dotted lines), in turn defined by the following parameters: $Q_{y}$ and $\delta_{y}$ given by Equations (1) and (2); the elastic stiffness $K_{e}\left(=Q_{y} / \delta_{y}\right)$; the force $Q_{B}$ at the onset of the second plastic branch given by Equation (1); and the first and second plastic stiffness, $K_{p 1}$ and $K_{p 2}$. The displacement $\delta_{B}$ associated with $Q_{B}$ is readily obtained from $K_{p 1}$ and $Q_{B}$. In Figure $17 \mathrm{~b},{ }_{s} \delta_{u}{ }^{+}$and ${ }_{s} \delta_{u}{ }^{-}$denote the maximum deformation accumulated in the positive and negative skeleton parts. The portion of the total plastic strain energy dissipated by the damper on the skeleton part, in the positive and negative domains of loading, respectively ${ }_{s} \mathrm{~W}_{u}{ }^{+}$and ${ }_{s} \mathrm{~W}_{u}{ }^{-}$, is readily obtained by integrating the areas enveloped by each skeleton curve in Figure 17b. The Bauschinger part is constituted by the segments of the $Q-\delta$ curve that start at $Q=0$ and end at the point corresponding to the maximum load attained in the preceding cycles in the same loading domain. The Bauschinger parts are graphically depicted in Figure $17 \mathrm{c}$, and the area enveloped in each domain of loading, ${ }_{B} W_{u}{ }^{+}$and ${ }_{B} W_{u}{ }^{-}$, represents the portion of the total energy dissipated by the steel element in the Bauschinger part.

For convenience, ${ }_{s} W_{u}{ }^{+},{ }_{s} W_{u}{ }^{-},{ }_{B} W_{u}{ }^{+},{ }_{B} W_{u}{ }^{-},{ }_{s} \delta_{u}{ }^{+}$and ${ }_{s} \delta_{u}{ }^{-}$, are expressed in a nondimensional form by:

$$
s \bar{\eta}^{+}=\frac{{ }_{s} W_{u}^{+}}{Q_{y} \delta_{y}} ;{ }_{s} \bar{\eta}^{-}=\frac{{ }_{s} W_{u}^{-}}{Q_{y} \delta_{y}} ;{ }_{B} \bar{\eta}^{+}=\frac{{ }_{B} W_{u}^{+}}{Q_{y} \delta_{y}} ;{ }_{B} \bar{\eta}^{-}=\frac{{ }_{B} W_{u}^{-}}{Q_{y} \delta_{y}} ; e p \bar{\eta}^{+}=\frac{{ }_{s} \delta_{u}^{+}}{\delta_{y}} ; e p \bar{\eta}^{-}=\frac{{ }_{s} \delta_{u}^{-}}{\delta_{y}}
$$

and the total energy dissipated on the skeleton part, on the Bauschinger part, and the total energy dissipated by the steel component until failure can be expressed in nondimensional form by:

$$
{ }_{s} \eta=\left|{ }_{S} \bar{\eta}^{+}\right|+\left.\right|_{S} \bar{\eta}^{-}\left|{ }_{B} \eta=\right|{ }_{B} \bar{\eta}^{+}|+|_{B} \bar{\eta}^{-}\left|{ }_{e p} \eta=\right|{ }_{e p} \bar{\eta}^{+}|+|_{e p} \bar{\eta}^{-} \mid ; \eta={ }_{s} \eta+{ }_{B} \eta .
$$

Past studies [12] showed that ${ }_{B} \eta$ and ${ }_{e p} \eta$ follow an approximately linear relationship:

$$
{ }_{B} \eta=a_{e p} \eta+b^{\prime},
$$

where $a$ and $b^{\prime}$ are two parameters determined from tests. 


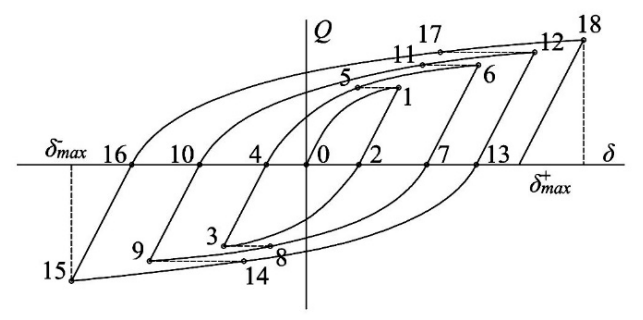

(a)

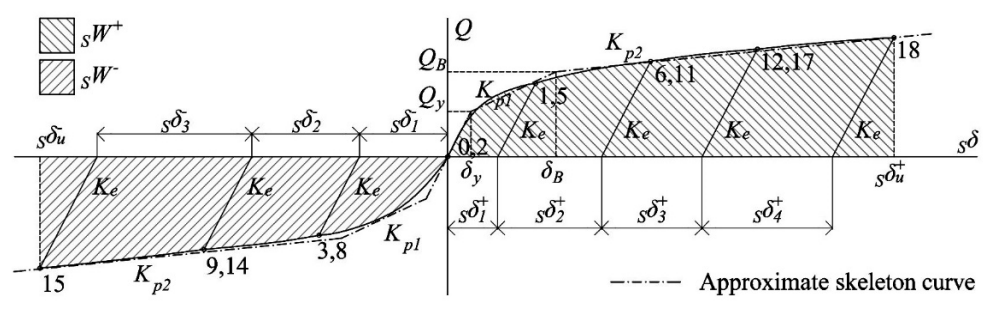

(b)

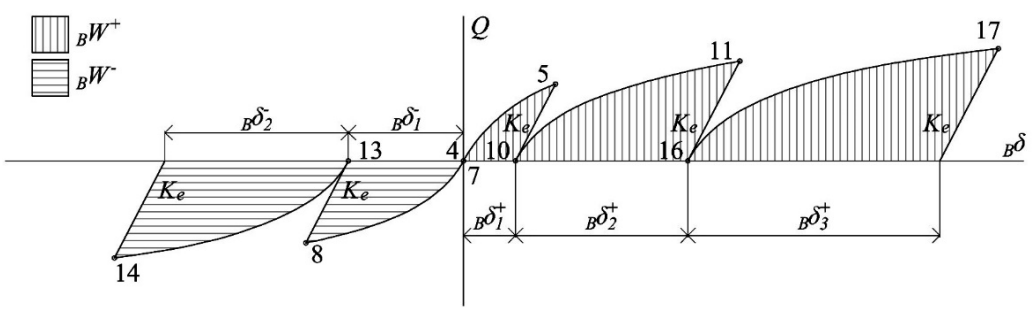

(c)

Figure 17. Decomposition of $Q-\delta$ curve: (a) overall curve; (b) skeleton part; (c) Bauschinger part.

The normalized $Q-\delta$ curves obtained in each test until failure (Figure 15) were decomposed as explained above and the values obtained for the nondimensional parameters defined in Equations (4) and (5) are summarized in Table 3. Figure 18 shows the normalized skeleton curves together with an approximated trilinear curve (bold dotted line) where $k_{p 1}=1 / 2.5$ and $k_{p 2}=1 / 14$. Figure 19a-c shows with circle, rhombus and square symbols the values of ${ }_{S} \eta_{B} \eta$ and $\eta$ at failure obtained from the tested specimens; they are plotted against $e_{e p} \eta$. The decomposition explained above was also done at each point of the normalized $Q-\delta$ curves of Figure 15, the corresponding values of ${ }_{s} \eta,{ }_{B} \eta, \eta$ and $e p \eta$ are plotted with solid lines in Figure 19. These curves represent the "energy dissipation path" followed by each test specimen up to failure. Also plotted in Figure 19a is a line (solid bold) with slope $a=-14.66$ passing through the point $(0,3900)$, which is found to fit the experimental results well. This value $a=-14.66$ is the one obtained in previous studies [12] for slit-type plates made of mild and high-strength steel; thus the results of this study indicate it is likewise valid for the slit-type plates made of stainless steel. As for parameter $b^{\prime}$, from the experimental results of this study it is proposed to adopt $b^{\prime}=3900$ for slit-type plates made of stainless steel. The value of parameter $b^{\prime}$ is a good indicator of the ultimate energy dissipation capacity of the damper. Comparing the $b^{\prime}$ obtained for the new SS-TTD damper- $b^{\prime}=3900$ - with that reported in previous studies on slit-plates made of mild steel [12] and high-strength steel [12] $-b^{\prime}=1325$ and $b^{\prime}=250$, respectively—it is concluded that 
the ultimate energy dissipation capacity of the stainless-steel slit-type plates that form the new SS-TTD is about three times larger than that of the mild steel slit-type plates, and 16 times larger than that of the high-strength steel slit-type plates.

Table 3. Ultimate energy dissipation capacity.

\begin{tabular}{cccccccc}
\hline Specimen & $\left.{ }_{e p} \bar{\eta}^{+}\right|_{e p} \bar{\eta}^{-} \mid$ & $\left.{ }_{S} \bar{\eta}^{+}\right|_{S} \bar{\eta}^{-} \mid$ & $\left.{ }_{B} \bar{\eta}^{+}\right|_{B} \bar{\eta}^{-} \mid$ & $\eta^{+}\left|\eta^{-}\right|$ & $\eta$ & $\mu_{C U M}$ & ${ }_{B} \eta /{ }_{S} \eta$ \\
\hline SS-TTD5 & 17.69 .3 & 3741 & 16431611 & 16801652 & 3332 & 1912 & 41.7 \\
SS-TTD6 & 22.528 .4 & 5466 & 17001633 & 17541699 & 3453 & 1728 & 27.8 \\
SS-TTD4 & 9.36 .5 & 1610 & 18841856 & 19001866 & 3766 & 2707 & 143.8 \\
\hline
\end{tabular}

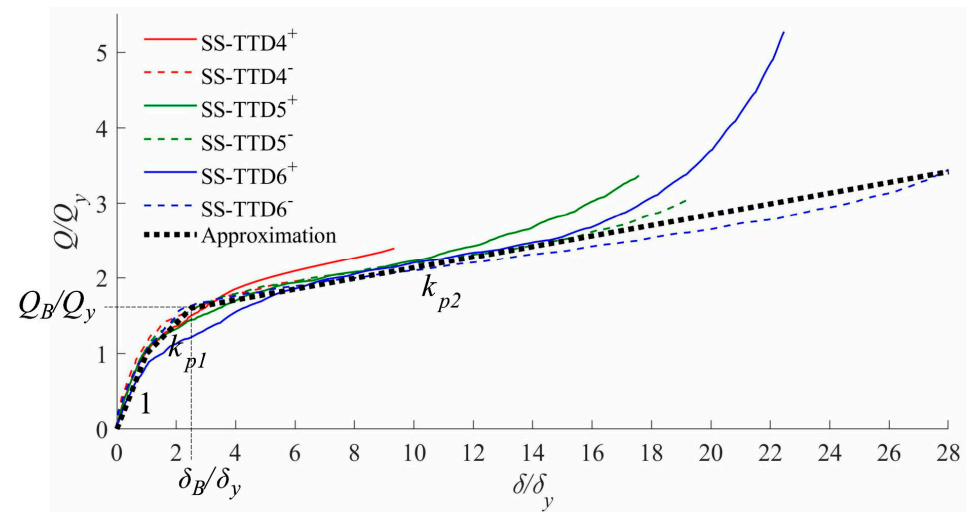

Figure 18. Skeleton curves.
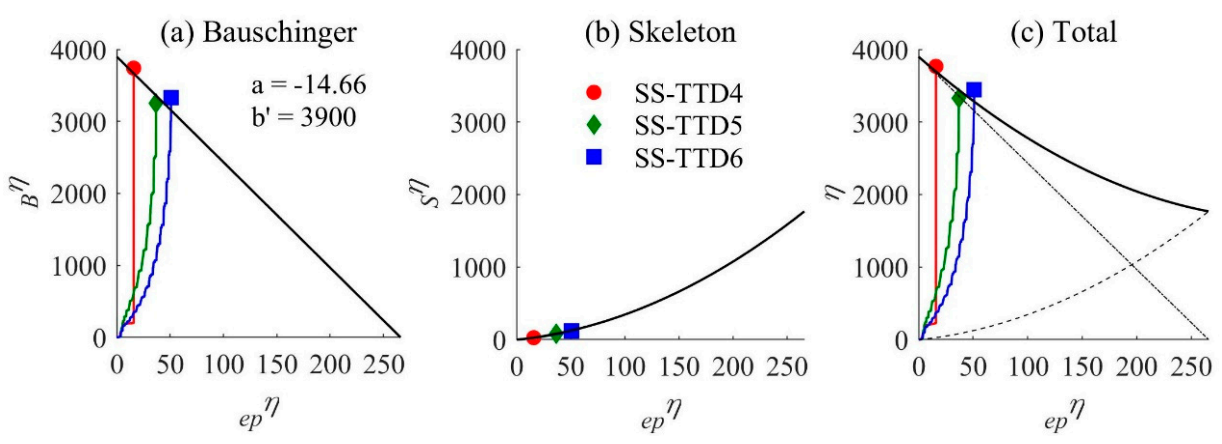

Figure 19. Ultimate energy dissipation capacity: (a) Bauschinger part, (b) skeleton part, (c) total.

The solid bold line in Figure 19b represents the normalized energy dissipated on the skeleton part against $e_{e p} \eta$. It was calculated using the approximated trilinear skeleton curve shown in Figure 18 with dotted bold lines. It is found to fit the experimental results very well (i.e., circle, rhombus and square symbols). Finally, the solid bold lines of Figure 19a,b were redrawn in Figure 19c (thin solid line and thin dotted line) and summed up to obtain the solid bold line of Figure 19c that represents the normalized ultimate energy dissipation capacity of the SS-TTD, characterised by parameters $k_{p 1}=1 / 2.5$, $k_{p 2}=1 / 14, a=-14.66, b=3900$ and the values of $Q_{y}, Q_{B}, \delta_{y}$ given by Equations (1) and (2). Once the ultimate energy dissipation capacity of the SS-TTD is determined, the failure of the SS-TTD under arbitrarily applied cyclic loading can be predicted from the $Q-\delta$ curve obtained up to each instant from numerical simulations (i.e., nonlinear time history analysis) as follows. At any instant $i$, the values of ${ }_{e} \eta \eta$ and $\eta$ are calculated from the $Q-\delta$ curve obtained up to instant $i$ as explained above, they are named ${ }_{e p} \eta_{i}$ and $\eta_{i}$ hereafter. Tracking this pair of points $\left({ }_{e} p \eta_{i}, \eta_{i}\right)$ and plotting them in Figure 19c, failure is expected to occur when the solid bold line is reached.

Previous studies [6-11] related the ultimate energy dissipation capacity of the damper to the cumulative ductility factor $\mu_{C U M}$ defined by Equation (7). In this equation, $\sum \delta$ is the sum of excursions of displacement experienced by the damper, normalized by the yielding displacement $\delta_{y}$. Figure 20 
shows the normalized ultimate energy dissipation capacity $\eta$ against $\mu_{\mathrm{CUM}}$ obtained for the SS-TTDs tested in this study until failure.

$$
\mu_{C U M}=\frac{\sum \delta}{\delta_{y}}
$$

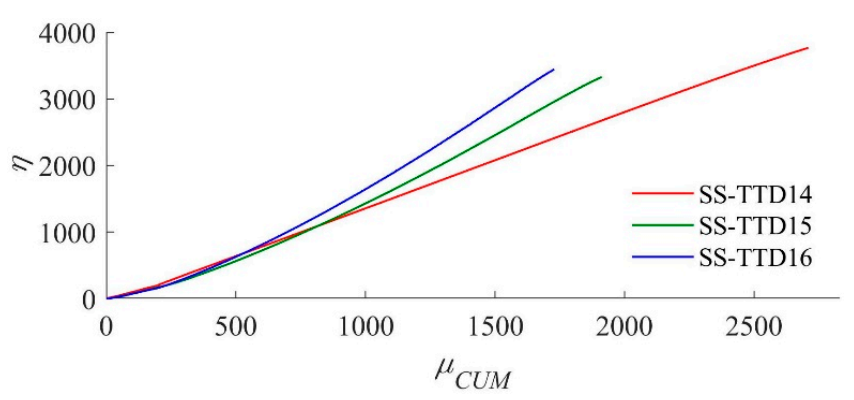

Figure 20. Normalized ultimate energy dissipation capacity against cumulative ductility factor.

The pair of values $\left(\eta, \mu_{C U M}\right)$ at failure obtained for the SS-TTDs are plotted in Figure 21 and compared with the values obtained in previous studies [6-9]. It is seen that the proposed SS-TTD has an energy dissipation capacity and an accumulated ductility notably larger than those reported for other dampers in previous studies.

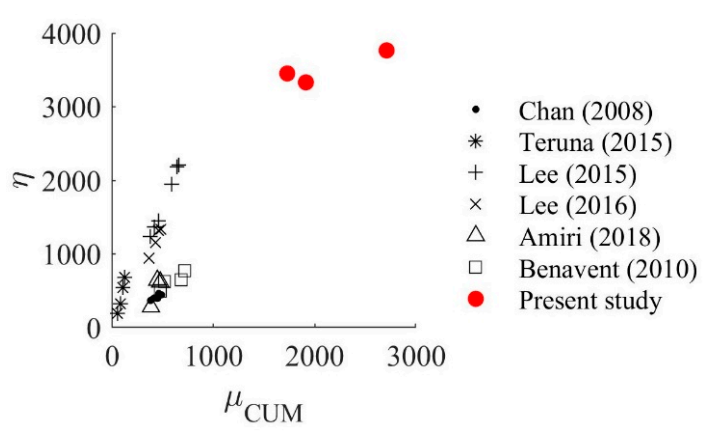

Figure 21. Comparison of the $\eta-\mu_{C U M}$ relationship between the selected references and this study.

\section{Numerical Characterization}

Two different numerical models were investigated to predict the hysteretic behaviour of the SS-TTD under arbitrary cyclic loadings. The first one is the polygonal model based on piecewise linear segments. The second one is a smooth hysteretic Bouc-Wen model [27], characterised by a continuous change of stiffness due to yielding and sharp changes from loading to unloading paths.

\subsection{Polygonal Model}

The polygonal model builds on the decomposition of the $Q-\delta$ loops into skeleton and Bauschinger parts explained in Section 4.2. The shape of the skeleton can be determined either experimentally with the procedure explained in Section 4.2 (Figure 18) or numerically. The shape of each Bauschinger curve is approximated by two segments (dashed and dotted lines) as shown in Figure 22. The slope of the first segment of this bilinear approximation is taken equal to the initial elastic stiffness $K_{e}$. The ordinate $Q_{m}$ of the end point of the second segment (named point 11 in Figure 22) coincides with the maximum force attained by the damper in previous cycles of displacement in the same domain of loading. The abscissa of this end of point is determined from the deformation ${ }_{B} \delta$. As discussed next, the value of ${ }_{B} \delta$ of a Bauschinger curve is very well correlated with the plastic deformation accumulated on the skeleton part, $\Sigma_{S} \delta$, up to the point where the Bauschinger curve starts. Figure 23a shows the pair of values $\left(\Sigma_{S} \delta\right.$, ${ }_{B} \delta$ ) calculated for each Bauschinger curve obtained from the tests conducted on the SS-TTDs in this 
study. An approximately linear relationship is observed between ${ }_{B} \delta$ and $\Sigma_{S} \delta$ that can be expressed by the bold dashed line of slope $\beta=0.35$, that is, ${ }_{B} \delta=0.35 \Sigma_{S} \delta$. Finally, the ordinate of the intersection point of the two segments is taken as $\alpha Q_{m}$, where the value of parameter $\alpha$ is determined so that the areas enveloped by the actual Bauschinger curve and by the bilinear approximations is the same. Figure 23b represents, in the horizontal axis, the actual values of $Q_{m} / Q_{y}$ for each Bauschinger segment obtained from the tests conducted on the SS-TTDs, and in the vertical axis, the value of $\alpha Q_{m} / Q_{y}$ that satisfies the above condition. As seen in Figure 23b, $\alpha$ can be taken as approximately equal to $\alpha=0.4$.

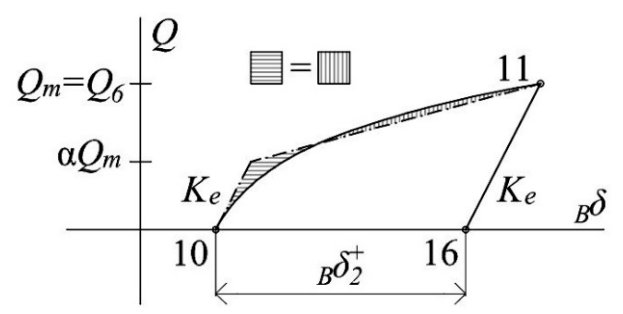

Figure 22. Idealisation of the Bauschinger parts.

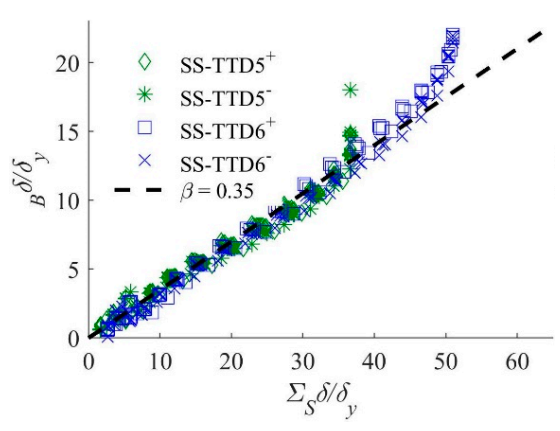

(a)

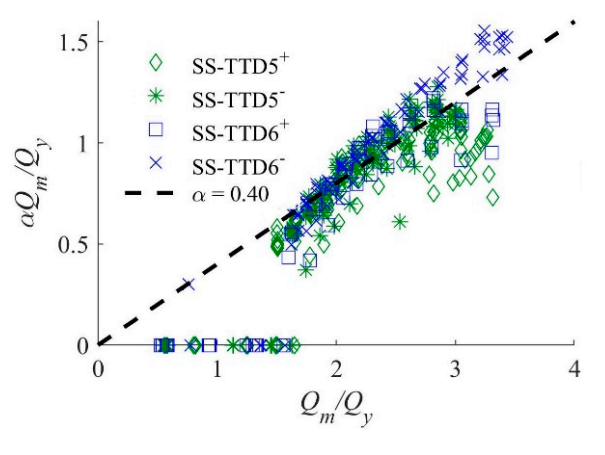

(b)

Figure 23. Modellisation of the Bauschinger part: (a) $\beta$ values, (b) $\alpha$ values.

\subsection{Bouc-Wen Model}

Although the Bouc-Wen model does not take into account the energy dissipation explicitly, it produces continuous curves that fit-better than the polygonal model-the actual shape of the $Q-\delta$ curves obtained experimentally. Moreover, it is implemented in well-known FEM software for structural analysis such as SAP2000 (Walnut Creek [CA], USA) [28] or OpenSees (Berkeley [CA] USA) [29]. The main parameters to define the Bouc-Wen model in SAP2000 are based on Wen's formulation [30]: (i) the initial stiffness $k_{0}$, (ii) the ratio of postyielding stiffness to the initial stiffness $\alpha^{\prime}$, and (iii) the transition parameter from linear to nonlinear range $n$. OpenSees has implemented a refined version of the Bouc-Wen model [27] that includes additional parameters to control the shape of the hysteresis loops $\left(\beta^{\prime}\right.$ and $\gamma$ ) and the strength degradation $(\Delta v$ and $\Delta \eta)$. These parameters were calibrated in this study to match the normalized $Q / Q_{y}$ versus $\delta / \delta_{y}$ curves obtained from the tests, giving: $k_{0}=1, \alpha^{\prime}=1 / 14, n=1.2, \beta^{\prime}=0.5, \gamma=0.5, \Delta v=-6 \cdot 10^{-4}$ and $\Delta \eta=1 \cdot 10^{-3}$. The Bouc-Wen equation implemented in OpenSees in terms of stress, $\sigma$, and strain, $\varepsilon$, is shown in Equation (8):

$$
\sigma=\alpha^{\prime} k_{0} \varepsilon+\left(1-\alpha^{\prime}\right) k_{0} z
$$

Here, $z$ is a variable that represents the hysteretic deformation and is related with the time derivative of the strain, $\dot{\varepsilon}$, by the following expression:

$$
\dot{\mathbf{z}}=\frac{1-|z|^{n}\left\{\beta^{\prime} \operatorname{sgn}(\dot{\varepsilon} z)+\gamma\right\} \Delta v}{\Delta \eta} \dot{\varepsilon},
$$


where $|z|$ indicates the modulus and sgn the sign. A detailed explanation can be found in [31]. More sophisticated Bouc-Wen-based models have been proposed in the literature to take into account the pinching and strain hardening effects [32-35]. However, a simplified model is adopted in this study since the realistic range of displacements expected on structures equipped with dampers $(\mu<9)$ are below the displacements associated with the onset of the second order effects that cause the pinching of the hysteretic loops $(\mu>12)$.

\subsection{Comparison and Validation}

Figure 24a,c,e compare the normalized $Q / Q_{y}$ versus $\delta / \delta_{y}$ curves obtained experimentally for specimens SS-TTD4, SS-TTD5 and SS-TTD6, with the prediction provided by the polynomial and the Bouc-Wen models under the same history of loading applied during the tests. The shape of the hysteretic loops provided by both numerical models is found to be close to the experimental results. The normalized $Q / Q_{y}$ versus $\delta / \delta_{y}$ curves obtained with the numerical models was decomposed into the skeleton part and the Bauschinger part (as explained in Section 4.2) and the energy dissipation paths in the $e_{e p} \eta-\eta$ plane were obtained. These paths are compared with the ones obtained experimentally in Figure 24b,d,f. In general, both models approach the energy dissipation paths obtained from the tests reasonably well. The approach is better ?particularly in specimen SS-TTD6? with the polygonal model than with the Bouc-Wen model, as was to be expected since the polygonal model is explicitly calibrated from energy dissipation considerations. Both numerical models predict the point of failure very well, with errors below $10 \%$. It is also worth noting that the polynomial model is not able to capture strength degradation effects under cycles of constant amplitude, whereas in the refined Bouc-Wen model implemented in OpenSees there are two parameters that allow this degradation to be reproduced. Nonetheless, the strength degradation is negligible as noted in previous sections, and the error accumulated in the predicted energy dissipation capacity due to ignoring this strength degradation is below $10 \%$, which is not significant in the overall response.

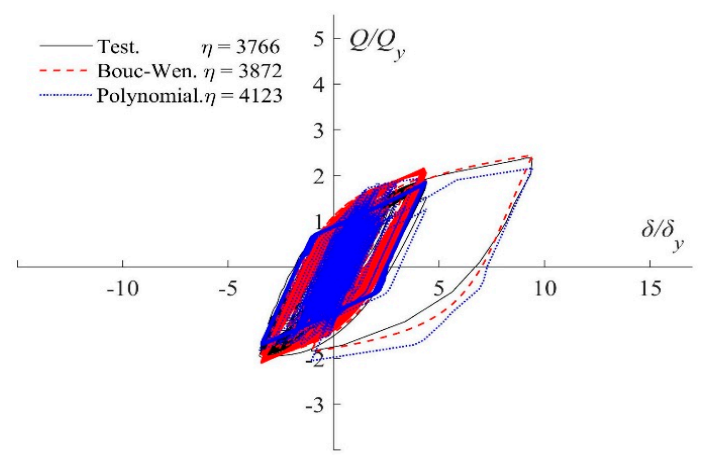

(a)

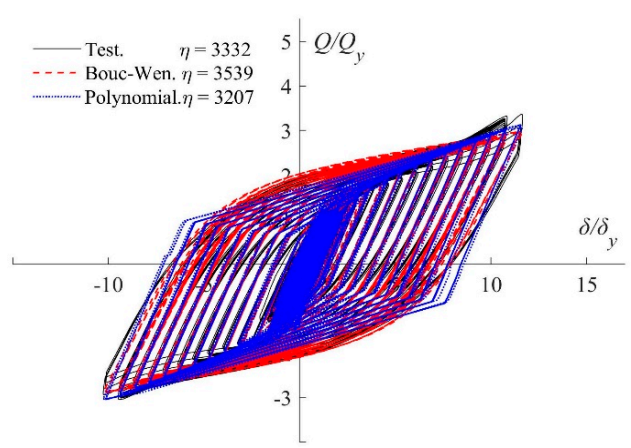

(c)

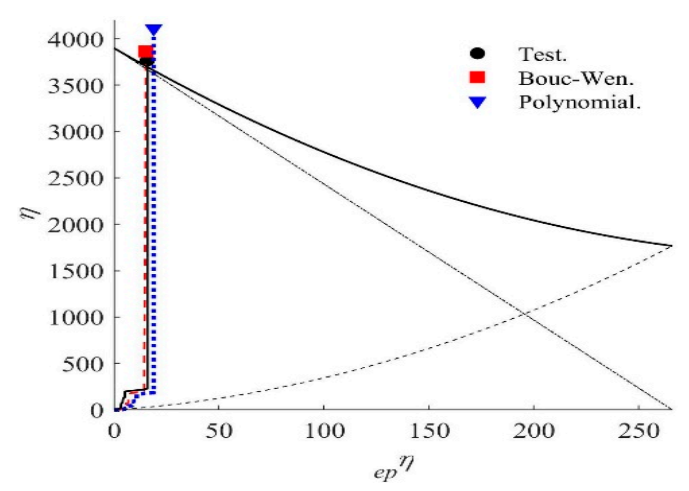

(b)

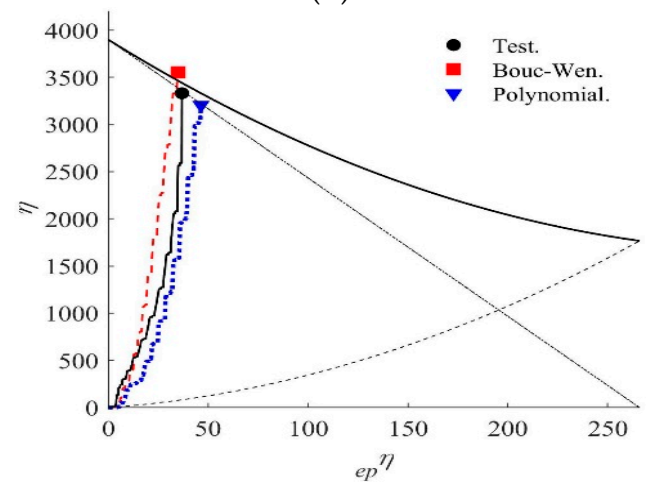

(d)

Figure 24. Cont. 


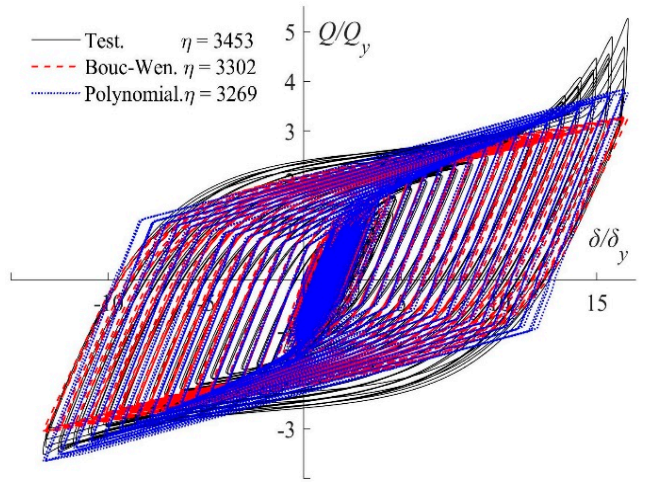

(e)

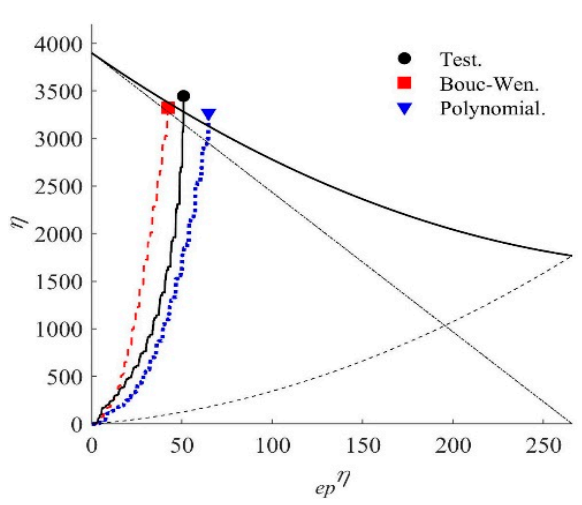

(f)

Figure 24. Comparison between test and numerical model simulations: (a) SS-TTD4 normalized $Q-\delta$ curves, (b) SS-TTD4 energy dissipation paths, (c) SS-TTD5 normalized $Q$ - $\delta$ curves, (d) SS-TTD5 energy dissipation paths, (e) SS-TTD6 normalized $Q-\delta$ curves, (f) SS-TTD6 energy dissipation paths.

\section{Conclusions}

This paper presents a new displacement-dependent damper, referred to as the Stainless-Steel Tube-in-Tube Damper (SS-TTD), for the passive control of structures subjected to seismic loadings. The SS-TTD consists of two tubes (inner and outer tubes) arranged in a telescopic configuration that can be installed in a frame structure as a conventional brace. The source of energy dissipation is the plastic deformation of stainless-steel strips achieved by opening slits in the walls of the outer tube. Stainless steel is used because its inherent energy dissipation capacity is larger than low-yield or mild steel, and is more durable against corrosion, thus reducing maintenance costs. The height-to-width ratio of the steel strips is made as large as possible?within the dimensional requirements imposed by architectural constraints?to guarantee a flexural-type yielding mode and to enhance the energy dissipation capacity. Three SS-TTDs were built and tested under dynamic and static cyclic loads. In the dynamic tests, the new dampers were installed in a RC waffle-flat plate structure and subjected to several ground motion simulations on a shaking table. In the static tests, the dampers were subjected to cycles of constant amplitude until failure. From the tests the following conclusions can be drawn:

- The new damper exhibits a stable hysteretic behaviour until failure, with minor reduction of the peak strength under repeated cycles of constant amplitude.

- For realistic values of the maximum ductility demand (3-9), the force-displacement curves are exempt from geometric nonlinearity effects that cause spurious increases of the restoring force; such geometric nonlinearities start at a displacement ductility larger than about 12 .

- The force-displacement curve of the SS-TTD was split into the so-called skeleton part and the Bauschinger part, and the ultimate energy dissipation capacity of SS-TTD in each part was quantitatively evaluated; furthermore, a procedure to predict the failure of the damper based on this decomposition is proposed.

- The ultimate energy dissipation capacity of the SS-TTD, expressed in terms of the amount of energy that can be dissipated consuming only the Bauschinger part, is 3- and 16-fold higher than that of slit-type plates made of mild steel and high-strength steel, respectively. Further, the cumulative ductility of the SS-TTD exceeds by more than four times the values reported in the literature for similar slit-type steel plate dampers.

- Two numerical models are proposed to characterise the hysteretic behaviour of the SS-TTD: a polygonal model based on the decomposition into the skeleton and Bauschinger parts of the force-displacement curves, and a smooth model that uses the Bouc-Wen formulation. Although both models adequately reproduce the response obtained experimentally, the former predicts the energy dissipation path and failure of the damper better, while the latter reproduces the shape of the hysteretic loops more accurately. 
Author Contributions: A.B.-C. conceived the damper and experimental campaigns as principal investigator of the grant funding the project; G.G.-S. performed the static tests, participated in the shaking table tests, and processed the experimental results; G.G.-S., D.E.-M. and A.B.-C. analysed the experimental results and obtained the conclusions; all authors contributed to writing the paper. All authors have read and agreed to the published version of the manuscript.

Funding: This research was funded by the Spanish Ministry of Economy and Competitivity, grant number MEC BIA2017 88814 R, and received funds from the European Union (Fonds Européen de Dévelopment Régional).

Conflicts of Interest: The authors declare that they have no conflict of interest.

\section{References}

1. Soong, T.T.; Spencer, B.F. Supplemental energy dissipation: State-of-the-art and state-of-the-practice. Eng. Struct. 2002, 24, 243-259. [CrossRef]

2. Spencer, B.F.; Nagarajaiah, S. State of the art of structural control. J. Struct. Eng. 2003, 129, 845-856. [CrossRef]

3. Saaed, T.E.; Nikolakopoulos, G.; Jonasson, J.; Hedlund, H. A state-of-the-art review of structural control systems. J. Vibrat. Control. 2015, 21, 919-937. [CrossRef]

4. Housner, G.W.; Bergman, L.A.; Caughey, T.K.; Chassiakos, A.G.; Claus, R.O.; Masri, S.F.; Skelton, R.E.; Soong, T.T.; Spencer, B.F.; Yao, J.T.P. Structural control: Past, present, and future. J. Eng. Mech. 1997, 123, 897-971. [CrossRef]

5. Javanmardi, A.; Ibrahim, Z.; Ghaedi, K.; Benisi Ghadim, H.; Hanif, M.U. State-of-the-art review of metallic dampers: Testing, development and implementation. Arch. Comput. Meth. Eng. 2019, 26, 1-24. [CrossRef]

6. Chan, R.W.K.; Albermani, F. Experimental study of steel slit damper for passive energy dissipation. Eng. Struct. 2008, 30, 1058-1066. [CrossRef]

7. Teruna, D.R.; Majid, T.A.; Budiono, B. Experimental study of hysteretic steel damper for energy dissipation capacity. Adv. Civ. Eng 2015, 631726. [CrossRef]

8. Lee, C.; Ju, Y.K.; Min, J.; Lho, S.; Kim, S. Non-uniform steel strip dampers subjected to cyclic loadings. Eng. Struct. 2015, 99, 192-204. [CrossRef]

9. Lee, C.; Lho, S.; Kim, D.; Oh, J.; Ju, Y.K. Hourglass-shaped strip damper subjected to monotonic and cyclic loadings. Eng. Struct. 2016, 119, 122-134. [CrossRef]

10. Amiri, H.A.; Najafabadi, E.P.; Estekanchi, H.E. Experimental and analytical study of block slit damper. J. Constr. Steel Res. 2018, 141, 167-178. [CrossRef]

11. Benavent-Climent, A. A brace-type seismic damper based on yielding the walls of hollow structural sections. Eng. Struct. 2010, 32, 1113-1122. [CrossRef]

12. Benavent-Climent, A.; Oh, S.; Akiyama, H. Ultimate energy absorption capacity of slit-type steel plates subjected to shear deformations. J. Struct. Constr. Eng. 1998, 503, 139-147. [CrossRef]

13. Nip, K.H.; Gardner, L.; Elghazouli, A.Y. Cyclic testing and numerical modelling of carbon steel and stainless steel tubular bracing members. Eng. Struct. 2010, 32, 424-441. [CrossRef]

14. The International Organization for Standardization (ISO). Metallic Materials. Tensile Testing. Part 1: Method of Test at Room Temperature; UNE-EN ISO 6892-1:2016; The International Organization for Standardization (ISO): Madrid, Spain, 2017.

15. Ministerio de Fomento. Instrucción de Hormigón Estructural. In Estructuras de Hormigón estructural (EHE-08); Centro Publicaciones: Madrid, Spain, 2008.

16. Ministerio de Fomento. Norma de Construcción Sismorresistente. In Parte General y Edificación (NSCE-02); Centro Publicaciones: Madrid, Spain, 2003.

17. Benavent-Climent, A.; Gale-Lamuela, D.; Donaire-Avila, J. Energy capacity and seismic performance of RC waffle-flat plate structures under two components of far-field ground motions: Shake table tests. Earthq. Eng. Struct. Dyn. 2019, 48, 949-969. [CrossRef]

18. ATC. Guidelines for Cyclic Seismic Testing of Components of Steel Structures; Applied Technology Council: Redwood City, CA, USA, 1992.

19. Cadoni, E.; Fenu, L.; Forni, D. Strain rate behaviour in tension of austenitic stainless steel used for reinforcing bars. Constr. Build. Mater. 2012, 35, 399-407. [CrossRef]

20. Lichtenfeld, J.A.; Mataya, M.C.; Van Tyne, C.J. Effect of strain rate on stress-strain behavior of alloy 309 and 304L austenitic stainless steel. Metall. Mater. Trans. 2006, 37, 147-161. [CrossRef] 
21. Lee, W.S.; Lin, C.F.; Chen, B.T. Tensile properties and microstructural aspects of 304L stainless steel weldments as a function of strain rate and temperature. Proc. Inst. Mech. Eng. Part C-J. Eng. Mech. Eng. Sci. 2005, 219, 439-451. [CrossRef]

22. Benavent-Climent, A.; Donaire-Avila, J.; Oliver-Saiz, E. Shaking table tests of a reinforced concrete waffle-flat plate structure designed following modern codes: Seismic performance and damage evaluation. Earthq. Eng. Struct. Dyn. 2016, 45, 315-336. [CrossRef]

23. Chopra, A.K. Dynamics of Structures; Prentice Hall: Englewood Cliffs, NJ, USA, 1995; Volume 3.

24. Benavent-Climent, A. An energy-based damage model for seismic response of steel structures. Earthq. Eng. Struct. Dyn. 2007, 36, 1049-1064. [CrossRef]

25. Kato, B.; Akiyama, H.; Yamanouchi, H. Predictable Properties of Structural Steels Subjected to Incremental Cyclic Loading. In IABSE Symposium on Resistance and Ultimate Deformability of Structures Acted on by Well-Defined Loads; IABSE-AIPC-IVBH Publications: Lisbon, Portugal, 1973; pp. 119-124.

26. Jiao, Y.; Shimada, Y.; Kishiki, S.; Yamada, S. Study of Energy Dissipation Capacity of Steel Beams Under Cyclic Loading. In Behaviour of Steel Structures in Seismic Areas STESSA; CRC Press: Boca Raton, FL, USA, 2009.

27. Baber, T.T.; Noori, M.N. Random vibration of degrading, pinching systems. J. Eng. Mech. 1985, 111, 1010-1026. [CrossRef]

28. SAP2000. CSI Analysis Reference Manual; Computers and Structures Inc.: Berkeley, CA, USA, 2017.

29. OpenSees. Open System for Earthquake Engineering Simulation; Pacific Earthquake Engineering Research Center: Berkeley, CA, USA, 2010.

30. Wen, Y.K. Method for Random Vibration of Hysteretic Systems. J. Eng. Mech. Div. ASCE 1976, 102, $249-263$.

31. Haukaas, T.; Der Kiureghian, A. Finite Element Reliability and Sensitivity Methods for Performance-Based Earthquake Engineering. In Proceedings of the Pacific Earthquake Engineering Research Center College of Engineering; University of California: Berkeley, CA, USA, 1 April 2004.

32. Noori, M.N.; Padula, M.D.; Davoodi, H. Application of an Itô-based approximation method to random vibration of a pinching hysteretic system. Nonlinear. Dyn. 1992, 3, 305-327. [CrossRef]

33. Sivaselvan, M.V.; Reinhorn, A.M. Hysteretic models for deteriorating inelastic structures. J. Eng. Mech. 2000, 126, 633-640. [CrossRef]

34. Wu, M.; Smyth, A. Real-time parameter estimation for degrading and pinching hysteretic models. Int. J. Non-Linear Mech. 2008, 43, 822-833. [CrossRef]

35. Bursi, O.S.; Ceravolo, R.; Erlicher, S.; Zanotti Fragonara, L. Identification of the hysteretic behaviour of a partial-strength steel-concrete moment-resisting frame structure subject to pseudodynamic tests. Earthq. Eng. Struct. Dyn. 2012, 41, 1883-1903. [CrossRef]

(C) 2020 by the authors. Licensee MDPI, Basel, Switzerland. This article is an open access article distributed under the terms and conditions of the Creative Commons Attribution (CC BY) license (http://creativecommons.org/licenses/by/4.0/). 